1936

\title{
Artificial fever therapy
}

Warren A. Shoecraft

University of Nebraska Medical Center

This manuscript is historical in nature and may not reflect current medical research and practice. Search PubMed for current research.

Follow this and additional works at: https://digitalcommons.unmc.edu/mdtheses

Part of the Medical Education Commons

\section{Recommended Citation}

Shoecraft, Warren A., "Artificial fever therapy" (1936). MD Theses. 466.

https://digitalcommons.unmc.edu/mdtheses/466

This Thesis is brought to you for free and open access by the Special Collections at DigitalCommons@UNMC. It has been accepted for inclusion in MD Theses by an authorized administrator of DigitalCommons@UNMC. For more information, please contact digitalcommons@unmc.edu. 
ARTIFIOIAL FEVR THERAFY

by

WARREA A. SHOECRAFT

SENIOR THESIS

1930

UNIVGRSITY OF NABRASKA COLLAGE OF WADICINE

ONAHA 
1. IIVTRUDUCTIUN................

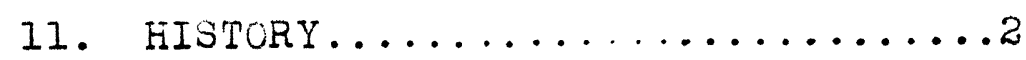

111. METHODS...................

(1) Infectious agents.......12

(a) Radiant heat..........14

(3) Hot water bath.........15

(4) Foreign Protein.........17

(5) Electric blankets........18

(6) High frequency energy .....20

(7) Kettering hypertherm......32

(8) Hot moist air chamber....39

(9) Conclusion...........40

2 V. TEMPERATURE REGULATION........43

V. PHYSIOLOGIC REACTIONS.........46

(1) Blood flow...........47

(2) Blood cellular elements...53

(3) Blood chemistry.........55

(4) Blood immune bodies......60

(5) Gestric secretion.......62

(6) Sweat.............62

(7) Urine .............6a

(8) Wetabolic rate........63

(9) Electrocardiogram.......64

(10) Conclusion...........64

VI. PATHOLOGICAL REACTIUNS.........65 
V11. COMPLICATIONS AND CONTRAIWLICATIONS. .71 V111. TEChINICAL CONSIDERATIONS.........76 IX. DISEASES TREATED..............83

(1) Gonorrhea..............84

(2) Gonorrheal arthritis.......88

(3) Chronic infectios arthritis...91

(4) Syphilis...............93

(a) Early .............95

(b) Neurosyphilis.........9?

(c) Tabes dorsalis........99

(d) Tabetic form paresis...100

(e) Diffuse C.in.S. syph....101

(5) Asthma...............102

(6) Multiple sclerosis..........105

(7) Corneal ulcer............108

(8) Lycosis fungoides...........109

x. CONCLUSion.......................

XI. BIBLIOGRAPHY................ 
INTRO DUCT ION 


\begin{abstract}
"Those diseases which medicines do not cure, iron (the knife) cures; those which iron cannot cure, fire cures; and those which fire cannot cure are to be reckoned wholly incurable!
\end{abstract}

Hippocrates

The living organism is in a figurative sense strung upon a very narrow margin in the scale of vital thermodynamics. Within this narrow sphere life's processes function normally. When in human and other warm blooded animals the temperature is made to rise or fall above or below the thermic level of thirty-seven degrees C., functional and metabolic variations ensue as demonstrated by acceleration or slowing of physiologic and vital activity. It has been stated that life is an adjustment of internal relations to external forces. Heat is undoubtedly the most equilibrating and $d \in f \in n s i v e$ force litilized by nature in the form of fever, and modern medicine is now learning to imitate nature by means of physical agencies to produce controllable temperature states.

Formerly regarded as undesirable and even dangerous, the symptom complex known as fever is gradually coming into recognition as a laudable and purposeful manifestation of defense by the living organism. Today it is 
the lack of fever in the presence of disease that is giving the profession its greatest concern. Instead of regarding fever as a passive force associated with toxic states, modern science is at present critically studying its use and advantages as an active therapeutic agent in a large variety of conditions. 
HISTORY 
It has become sort of a fashion among those who write about the therapeutic value of heat to trace it back to the Romans and Greeks. What a tremendous burden of responsibility has been placed on the Romans and Greeks.

We know from fiomer that warm baths must have been established among the Greeks more than three thousand years ago. This is referred to by Pope, especially in the passage in which Ulysses gives a glowing description of the bath prepared for him by the Nymphs of Circe during the siege of Troy in the year 1194 B.C.

"That in the tropod air the kindled pile, The water pours; the bubbling waters boil; An ample vace recieves the smoking wave, And in the bath prepared my limbs I lave, Receiving sweets repair the mind decay, And take the painful sense of tail away."

\section{Pope}

The Greeks were most probably the first who converted their thermal springs into capacious baths. There were several baths that were early famous for the cures ascribed to them and later cultivated by their priestphysicians.

Before the birth of Jesus Christ, the Jems also had their thermal baths, renowned for the curative virtues 
they were believed to possess. Josephus mentioned the warm baths at enunans, fanous for the recovery of the health of the body, near which the Emperor Tiberius built a city and called it riberius.

The most celebrated baths of ancient times were those at Bair, Naples and Ischia. The Romans had statues erected at these baths, each with a finger pointing to that particular spot of the body for the disease affecting which it was believed the waters of the bath possessed a special remedial power. During the height of the Roman Impire (3I) there were in Rome proper more than sixhundred public bathing establishments, some of which were imposing and enormous institutions such as the baths of Caracalla and those of Deocletian. At these places were a series of pools in which water was kept at different temperatures from hot to cool. It was the custom of the young bloods of Rome to go to these bathing establishments for a hot bath and rub, followed by epilation and by annointment with various aromatic and cosmetic preparations. Such practices can hardly be looked upon as therapeutic procedures. They smack altogether too much of ordinary hygiene and cosmetics efforts. The use of heat under such circumstances can hardly be dignified by the neme of heat therapy. The Hhommans of Egyot is another proof of the antiquity of the hot bath for its health giving value.

It is possible that very hot baths were used in 
China (101), for Chang-ji, a physician of the period 25 B.C. used the expression "boiling water boil bath" and $1056 \mathrm{~A} . \mathrm{D}$. in a medical book on therapeutics the description, "a hundred times boiled bath" was used. The empirical use of heat for relief of various ailments was undoubtedly used as extensively and with about as much knowledge among the Chinese as the Romans. However, like many other therapeutic measures the knomledge of the beneficient action of heat by the ancients vas empirical and enshrouded with magical formulas and superstitions.

The Japanese were the first modern people to use intensely hot baths solely for therapeutic purposes (86). This was because of the natural occurrence of hot springs in conjunction with the volcanic formations of the islands. These people immersed themselves to the neck and poured the hot water over their heads with wooden dippers. Thus they remained immersed for variable periods, chanting a song while the bath master shouted encouragement from time to time. After about six minutes of this $r \in f i n e d$ torture, the bobbed out almost parboiled with a body temperature ranging from 103 to 105 degrees $F$. These thermal springs were renowned for their curative effects in all forms of syphilis, arthritis, rheumatism, acute genital urinary infections, and respiratory, digestive, nervous and ocular diseases. 
Even in tropical Africa the principle of baths prevails and is variously applied for curative purposes. The inhabitants of most of the maritime localities in the Bights are fully acquainted with the importance of these views, and treat remittent and other fevers to which they are subjected by endeavoring to excite a long continues and copious exudation of sweat by the aid of hot sand and hot water (101).

The American Indians are known to have employed hot baths for treating diseases, especially acute fevers. In william Penn's comrunication to Dr. Edward Baynard, Fellow of the Royal College of Physicians, there is mentioned an acoount of the discovery by an Indian chief's air vapor treatment of his illness, with almost immediate relief.

In more recent years, many authors have laid stress upon the thermal quality of hot springs in surope and America.

Hot mineral springs have been very extensively advertised for their curative effects. In 1893 Draper (33) probably touched the true value of the numerous hot springs when he said, "That in bathing cures the beneficial effects are mainly due to the thermal qualities of the water and the methods of their application, there being no sufficient evidences that absorption of their mineral ingredients 


\section{History}

through the skin playing part in their therapeutic effects!

The laity has always been certain of the curative value of external heat. Everyone remembers the hot baths followed by sweats given by parents in a laudable attempt to overcome bad colds and kindred infections of the respiratory tract. Sweat baths were frequently prescribed by the general practitioner of the middle nineteenth century and rest on a perfectly logical basis of common sense and experience.

That fever, however, must serve some very useful purpose, or nature would not have retained it so tenaciously as a reaction process to invasion of harmful substances was the conclusion of welch (120) and others, who in the past forty years, have fostered a return of the former idea of fever's beneficence.

While it is true that the general temperature elevation has been an established therapeutic procedure ever since the ancients, its scientific and critical use is very recent. The fever $t$ erapy, as we know it now, originated with wagner Jauregg in 1978. It was he who found that innoculation of a patient suffering from paralytica dementia with malaria was often followed by improvement or complete remission of symptoms. Although the therapeutic effect of the fever produced by malaria was recognized at once, it has been in the last eight years only that complete 
study of value and methods of producing artificial fever has been made. Today scientifically trained men such as Carpenter, Witney, Ney ann, Bierman, Simpson, and others are devoting much of their time to the field of artificially produced therapeutic fever. The methods and clinical findings of these men will be found further on in the text. 
WELCDS

11 
There are six general methods for producing fever in man for the rapeutic purposes: infectious agents, radiant heat, hot water baths, foreign proteins, electrical energy and air conditioned cabinets. All of these methods depend upon heat which must either be produced by and within the body or supplied from without by some form of energy that is transformed to heat when applied to the body.

\section{Infectious Agents}

The use of living infectious agents for the treatment of dementia paralytica, especially the work of WagnerJauregg with Plasmodium malaria, has greatly encouraged the study of fever therapy. A great many agents have been used. Relasping fever was first used by Plaut in 1920. Rat bite fever was used by Solomon (108) in 1920.

$$
\text { Wagner- Jauregg used typhoid bacilli also for }
$$

the production of febrile reactions. Nevertheless, with the introduction of more modern methds of producing fever, the use of infectious agents has fallen into disrepute, while the physical agents have gained in desirability. The administration is accompanied by certain disadvantages.

Kobak (65) says, "Thile hyperpyrexia is the common phenomenon created by all measures, our choice must necessarily be influenced to avoid objectional or prevocative factors. Thus to cure a disease by imposing another disease, even though the latter is also curable, is an objection not borne out by sentiment alone. There is evidence 
at hand to prove that malaria carriers have infected other patients in the same institution. The controlability of fever produced by physical agents coupled with the elimination of possible infections are in them selves sufficiently valuable to swing general sentiment in their favor."

The advantages of therapeutic fever as compared with malarial treatment of paresis have been well summarized by King and Cocke (60). These are:

1. It is always available

2. No pathogenic organisms of unknown effect are injected into the patient

3. The frequency, duration, and intensity of the febrile paroxysms are under accurate control

4. The desired elevations can be produced in all cases, which is advantageous in cases that have an immunity to malaria

5. Drug therapy can be used in conjunction with this form of pyretotherapy if desired

6. Since the frequency, duration and intensity of the fever can be accurately controlled, the reaction produced in each patient can be nearly standarized

That these advantages of mechanically produced fever over types in which infectious or other foreign agents are 
administered would apply in other conditions as weIl as paresis is apparent.

Carpenter (25) likewise believes the administration of infectious agents is accompanied by the disadvantages listed.

Some of the older men who pioneered in the use of malaria in paresis do not believe fever produced by physical means brings about as good results, claimine malaria has a specific biological effect other than the fever. They do not believe a fever can be produced high enough to kill the spirochaete. Carpenter (25) seems to have disproved this when he showed that the spirochecte dies at $4 I$ degrees $C$.

\section{Radiant heat}

Radiant heat is a method of exposing the body to hot air, with a temperature that can be withstood by the skin of the body. The air surrounding the body may be heated in various ways, but in all cases arrangements must be made to prevent heat losses. Many experiments on heating the bodies of animals by this method have shown that such a method is practical although the peripheral structures of the body are heated first, ano the heat is then conducted to the enclosed viscera. (25)

External heat was first applied by Kahler and Knollmeyer in 1929 with the idea of producing artificial fever. They used an ordinary insulated cabinet in which were a number of mazda bulbs. 
In 1933 Hoverson (51) devised a cabinet for treating general paresis. This apparatus has been used with more or less success at the Kankakee State hospital. It consisted of a well insulated wooden cabinet, in which twenty-four lights were arranged in a series of twelve each, such an arrangement permitting the use of a greater amount of heat in producing a desired temperature, and of lesser amount to maintain a given temperature with comfort. The current was an ordinary 220 D.C. The bulbs were of thirty watts, shielded by wire netting. Desjardins (31) says that one thing in favor of radiant light fever chambers is that they are less expensive than other forms of apparatus. An objection, however, is that with the majority of such chambers, the elevation of the temperature is rather slow. In treating certain conditions which require that a high temperature be maintained for several hours undue slowness in inducing fever becomes a rather important objection because the patient becomes fatigued before his temperature has attained the level at which it is to be maintained for some time.

$$
\text { Hot Water Baths }
$$

Hot water baths have been used throughout the ages for their curative effects. However, it has been only in comparative recent times that man has realized fever could be produced by hot baths and that the curative effects were due to this fever. 
In 1883, Phillips clearly demonstrated and reported the fact that fever could be induced in man by means of hot baths. This form of artificial hyperpyrexis was $r \in d i s c o v e r e d$ and applied to animal experimentetion by Weichbrodt and Jahnel in 1919.

The first men to seriously consider the use of hot baths as a method of producing artificial $f \in v \in r$ with which to combat disease were Schamberg and Tseng (101) who, in 1927, made intensive study of this method of treating different forms of syphilis. They proved it possible to raise the temperature of the body as high as 106 degrees F. This method proved to be of therapeutic aid when used as an adjunct to other methods in the treating of syphilis. In 1929 Mehretens and Pouppirt (74) used hot baths in the treatment of syphilis. In the beginning of their work, they used an ordinary bath tub. Later after suggestion by Rosanoff (98) they utilized a continous bath. A thermocouple was utilized to obtain rectal readings at intervals of five minutes. They found the best temperature between 103 to 105 degrees F., the patient being quiet and rather apathetic.

With the advent of electrical aporatus for producing artificial fever, hot baths have not been used to any great extent.

Carpenter (25) says this method is impratical if 
the fever is to be mainteined for several hours. The prolonged hydrstatic pressure from vithout may cause passive congestion of the abdominal viscera. Desjardins (3I) says, "Hot baths can be used effectively when the period of fever need not be long, but when it is desirable to maintain the fever for an extended period of time, this method becomes a distressing and debilitating experience for the patient and is difficult to use satisfactorily."

\section{Foreign Proteins}

Injections of foreign proteins for stimulating febrile reactions in man is a common ractice. (68) Carpenter (25) states sterile milk, tuberculin, killed cultures of $B$. typhosus and other proprietary preparations have been used with various degrees of success. However, he also says the uncertainty of the agents in producing $f \in v e r$ is well known, and as a rule they do not produce sufficient elevation of body temperature to be of great value. A second disadvantage is that toxic substances are frequently introduced, especially when vaccines are used, which moy be injurious to the patient. The inability to control reacions that may follow such injections is a third undesirable factor. Desjardins (31) agrees with these disadvantages.

Recently Urechia (112) advocated preparations of 
urine for stimulating fever. Undoubtedly it is the chondromucoid substance in the urine that produces the febrile reaction, and the same disadvantages found in other foreign proteins would apply to this also.

Sulphur in oil was recommended for treatment of dementia paralytica by Schroeder (102) of Lemmark in 1929, the primary object of the therapy being to produce fever. This method has met with but little approval. Read and Mackay who use this therapy at the elgin state hospital are the only Americans who are fincing it beneficial

\section{Electric Blankets}

Wilgus (119) introduced the electric blanket in 1931. The original blanket was a very simple affair consisting of a lare electric heating pad in an ordinary blanket. At that time he claimed to have produced no burns and believed his apparatus simple, safe, and efficient and superior to an previously used method of fever production.

iveymann (85) tried out a blanket similar to that usea by "wilgus but did not report such encouraging results. During the treatments sweat, a good conductor, seeped into the blanket; short circuits resulted. The blanket caught afire and as Neymann said, "The patient is cooked in his own body fluia." A number of severe burns were produced. Neymann concluded that a blanket not absolutely moisture proof was totally unsuited for fever production. Eventually 
a new blanket was evolved with wires of enough tensile strength to resist breakage for many months. They were vulcanized in pure gum rubber and the temperature could be controlled by a rheostat.

Epstein (37) in 1934, devised a blanket which he believed satisfactory. It resembled a large heating pad unit and consisted of a heating element in the form of a rubberized blanket with a fine wire mesh, which provided the heat and might be used on either alternating or direct current. The patient was placed in a sleeping blank et equipped with zippers. This was covered with waterproof material and insulated. Within the bas there was provided a terry-cloth sheet which permitted absorption of sweat. Epstein claimed these advantages:

1. It is simple and inexpensive

2. It is easy to handie and easily transported; it is therefore available for private patients.

Epstein has used this blanket since 1934 and very recently (36) has reported continous satisfactory results, although he does admit some patients find the blanket nacomfortable due to weight of the blanket and accessories and the restriction of movement of body and limbs. Merriman and Osborne (76), in 1933, found the use of the blanket to be dangerous and hazardous procedure. It also was the most uncomfortable, slowest, and exhausting treatment usea. 
Methods

Other men have not found the electric blanket satisfactory. Neymann and Osborne (87) tried out the revised blanket in 1934, and although no burns were produced, they found the blanket treatments were more exhausting to the patient than diathermy or radiothermy.

\section{High Frequency Energy}

Discovery of the high frequency electric currents, so far as their clinical apolication is concerned, was made by d'Arsonval in 1889 and 1890 . He found by increasing the number of reversals of waves per second administered in tetanizing a muscle that the phenomenon of excitation was proportionately increased until a maximum of 2,500 to 5000 reversals per second was reached. At this point an increase in frequency of the alternations resulted in a progressive decrease in the vigor of contractions. In 1890 employing the wireless apparatus of fiertz, he was able to obtain billions of oscillations a second, by which means he succeeded in abolishing all sensation and miscular contractions and thus establishing for the first time high frequency currents for clinical application. (111) Diathermy

Neymann and Osborne (86) believe they were the first to use electropyrexia. They say they consulted a physicist in 1925 who said that the diathermic current little if any heat within the tissue. Seemingly the physicist had not read that dArsonval ait Charrin, in 1896, 
were able to demonstrate that there was a heating effect of high frequency current passed through the body. Neymann and osborne seem to have been unaware of this also. Nevertheless, they attempted to heat up the brains of dogs and were unsuccessful. During the experiments, they discovered the temperature of the body of the animals hed been increased. They conceived the idea of elevating the whole body temperature by means of the passage of laree amounts of current through the electrodes placed on the chest, abdomen and back.

In 1927, Christie and Binger (26) showed that the passage of high frequency current through any part of the body will cause an increase in temperature of the part. Hosmer (50), in 1928, demonstrated the heating effect of high frequency currents on salt solution of various concentrations and on small laboratory animels.

Probably Carpenter (25) has done mre work with various types of short wave apparatus than any other man. He employed the term diati ermy for the method in which large flexible, block tin electrodes are bound anteriorly and posteriorly over the ihorax of the patient, and a high frequency current is passed through the body. Due to the resistance of the body to the passing current, heat is produced locally between the electrodes and is conducted through the other tissues of the body by the circulation of the blood. 
In attempting $t$ find methods of fever production that would do away with the disadvantages of malaria King and Cocke (60) in 1930, used diathermy in treatment of paresis. King claimed that he ana H.L. Root has devised the diathermy machine in 1928.

In 1932, Bishop and others (20) made a clinical study of artificial hyperthermia induced by high frequency currents and used diathermy quite sucessfully. After preliminary work on dogs they set the limit of therapeutic fever at 4 degrees $C$. for patient. They also found that the most uncomfortable period for the petient occurs betreen 39 to 40 degrees $C$.

Mortimer (80) did research on animals with diathermy, summarizin his results. The effect was explained on a basis of heci production. Long continued sublethal does given to rats ana dogs were without ill effects. The leth al effects of these currents could be accounted for on the basis of over heat production. In live dogs the various organs heated up at approximately the same rate, the blood serving as an efficient distributing mechanism. Wost of the men wo worked early with diathermy found that fever was produced satisfactorily but that there were certain dangers connected with it. Contact with electrodes were often broken and serious burns resilted. Epstein (37) modified the electrodes, in 1935, in- 
to a set of cuff and belt electrodes consisting of chromium plated bress plated, segnented and hinged to fit the individual patient. These he claimed pratically eliminated dangers of burns.

Desjardins (31) believes diathermy has certain disadvantages. Contact with electrodes may be broken by movements of patient and burns may result. Woreover, such a method makes it impossible to keep the skin beneath the electrodes under observation. Another objection is that the fairly tight lacing of the jackets, which is necessary to maintain the ejectrodes in contact, gives the patient a sense of constriction and respiratory oppression that is decidedly uncomfortable.

To overcome further the disadvantages the electrodes have quite recently been modified by Gale (42). In January 1936, he developed a new air-spaced cuff electrode. Yost old types of electrodes were spaced from the skin surface by felt or some other interposed dielectric. Burns are common with this type. Gale's cuff type of electrode uillizes the principle and advantage of air spacing. A series of small bridges of non-conducting meterial are grooved so as to be readily applied to a standard rubber insulated cuff electrode. These briages are arraned to permit several different spacings of the rubber insulated electrode from the skin. The portion of the briage coming in contact wit the skin is well outside the field of maximum intensity 
thus avoiding concentrations or heating of the dielectric. The surface of the skin exposed to the field is open to air which permits free evaporation of moisture thereby avoiding the minute beads of perspiration which cause field concentrations anc burns.

In the hands of men experienced with the use of diatherny apparatus this method for producing artificial fever seems to be quite efficient. Diathermy is a comfortable method. Undoubtedly this comfort has a physiological basis because the heating is more internal and not at the expense of the delicate nervous mechanism of the skin as in the case of external applications. (76)

The only contraindication given by the men who favor diathermy is its use in pe ople with excessive adipose tissue. These do not tolerate diathermy rell. In these it is inclined to cause liquifection and a leaking out of the fat into the surrounding connective tissue. Radio the rmy

Dr. W.R. Witney, Director of the Reqearch Labor tory of the General Electric Company, had noticed that the men vorking in the field with a short wave transmitter had a rise in temperature. He was interested in the work on paresis by wagner-Jauregg and thought possibly a machine could be developed which would produce artificial tempereture which could be controlled at will. The outcome of his observation was the radiotherm. 
Carpenter and Page (24) first described the radiotherm in 1930 . They designated radiothermy as the method used for the heating of the body in a field of short radio waves that are broadcasted from two condenser plates. The energy derived from a short wave oscill: tor which is designed especialIy for this method of heating.

The subject is placed between the plates of a large condenser which forms part of an oscillating circuit. The oscillations in this circuit are produced by the use of radio tubes of appropriate construction with the necessary associated equipment for the attainment of a high frequency electric field of high intensity. The condener plates between which the subject is placed are large enough to produce a field over a reasonable part of the volume of the subject and are separated from one another by a distance of approximately one meter. The subject rests upon a canvas stretcher between these plates, but not in contact with them. To prevent loss of heat the entire body, with the exception of the head, is covered by means of a hood. The air inside of the hood is heatea by means of a hot air blower placed at one end. (12)

The term "radiotherny" is not used by all men in the field for this particular type of apparatus. Some men use the term "ultra high frequency" to differentiate radiothermy from diathermy. Bierman, like Carpenter, uses the term radiothermy. kobak (64) calls it "radiathermy" 
He believes this at once presents a composite picture of the action and nature of this form of energy. It is etymologically correct, terse and comprehensive.

others (1) have suggested the term "short wave diathermy! This emphasizes the relationship of the agent to the original aiathermy current.

The comptition of terms only ados to the confusion of the issue. As it was carpenter who developed the method, it would seem only correct to use his term, radiothermy.

The essential difference between diathermy and radiothermy is that the waves of the diathermy demand that electrodes be placea in good contact with the skin, while the ultre-short waves acts by having the plates near the body with an intervening air layer between them. The diathermy waves have the least effect on the bones and joints and mosi on muscle, whereas the ultra-short waves act on all of these as well as on the deep-seated organs and can be directed a considerable degree. (110)

Carpenter (25) concluded that satisfactory fever could be produced with either method. He believed the advantages of diathermy over radiothermy to be primarily one of economy. The short rave oscillator is more complicated and expensive equipment. The use of radiothermy is more comfortable for the patient because he is free to move about in the chamber, and his respiratory movements are not interferred with as in diathermy. The body is more uniformly 
heated in a field of short radio waves. Nursing care is simpler with diathermy.

Carpenter concluded the use of either of these methods is superior to other types. The height of the temerature can be controlled at will by increasing or decreasing the amount of energy supplied.

Neymannand others (85) likewise favor short wave heating. He states, "The method on robust patients makes little difference. But those who are marasmic and have chronic ailments should not be treated by external heat. To this category belong severe asthmatics, advanced cases of organic nervous disease, and patients suffering from various serious organis heart diseases. These patients may, however, be treated by diathermy or radiothermy"

\section{Inductotherm}

A high frequency generator, especially designed to generate heat within the living tissues by electromagnetic induction was developea by erriman and others (77) in 1934. This apparatus meets the requirements of the field of medical diathermy. The clinical application of the inductotherm, as the apparetus is called, both for local treatment anci the production of electropyrexia is extremely simple, $r \in q u i r i n g$ merely the placing of a few turns of insulated cable around or about the parts to be treated. No metal electrodes are applied, and burns such as those which 
may result from imporperly applied surface electrodes are, of course, prevented.

The inauctothermy is a vacuum tube oscillator, generating an alternating current with a frequency of approximetely $12,000,000$ cycles per second. The current is conducted through flexible, heavily insulated cable which is mond around or about the part to be treated. This cable may also be moulded into a pancake type of coil to be placed over the tissues which it is desired to heat.

ithin the coil, through which the current from the device flows, there is set up an alternating magnetic flux, having the same frequency as the current in the coil. If a conductive material is placed within the coil, an electromotive force will be induced in it. As a result of this induced voltage, eddy currents of the same frequency as the exciting current will flow in the concuctive material.

To produce fever the patient is placed in a treatment bag and two turns of the flexible cable placed around the patient outside the bag.

of twelve fever treatnents given to patients who had previously been subjected to other methods, including hot baths, radiant heat and infra red cabinets, electric blankets and diathermy, there was more comfort with the induc to therm. 
The inventors claim efficient heating, ease of application, and comfort of the patient.

A one tube inductotherm has very recently been accepted by the Council on Physical Therapy of the American Wedical Association. (30)

Selectivity of short waves

Tenney stated it was possible that the heating effect of short waves might be selective in character. Schereschewsky believed in 1926 that certain wave lengths (those between 15 and 3.8 meters) have a specific letral action upon living cells not attributable to the heating effect. since then several authors have reported a selective heat production of short waves. According to Gale (43) there is an optimal wavelength for heat production in any material depending upon its dielectric constant and electrical conductivity .

Investigations by Christie (26) and Kahler (56) tended to disprove any specific lethal action.

Wiggers (117) in 1932, thought the passage of radio waves might have a specific effect apart from thermal because the blood pressure was elevated, not decreased and that the force of ventricular contraction increased rather than decreased. Experiments were made in which heart temperature was recorded. hen radiothermy was discontinued for short intervals, the heart temperature remained the same but the systolic and diastolic pressure decreased 
promptly after interruption and mounted again aft $\in \mathbf{r}$ resumption. However, they did not believe these observations predicate that changes aside from local thermal variations in cardiac muscle occurred.

Desjardins (32) who champions the Kettering apparatus, an external source of heat, says the blood pressure rises before the temperature with the Kettering machine, but explains this on a physiological adaptation of the body to any increase in temperature, not to a specific selectivity.

Mortimer and osborne (82), in 1935, working for the Council on Physical Theraoy of the American Medical Association, concluded that there is no specific bilogic action of high frequency current, its effects being due solety to heat production.

Soon after this report wortimer and Beard (81) tested nine new short wave diathermy machines for their ability to heat human tissues. From their findings they concluded that there is no advantage of any one wave length over another for heating purposes. Conclusion

As may be seen the subject of short wave fever therapy is still a matter of controversy. Few procedures in modern physical medicine have passed th ough the gamut of extreme opinion as Hertzian short wave radiation. One 
group of workers produce enitrely diferent results from another group. The negation of proclaimed date has been the consequence.

However, there can be no doubt that short and ultra short wave therapy offers possibilities which cannot be ignored. The present controversial points will in due time bear natural fruits when cultivated by exact and uniform laboratory and clinical studies.

Kettering Hypertherm

Int $\in$ nsive study of fever therapy has been made a.t the fia valley hospital by Simpson. (106) To determine the possible value of this form of therapy it was necessary to develop fever producing apparatus which would give optimal comfort and safety to the patient and provide simple and convenient methods of control by the physician and nurse technician. Fis early experiences with diathermy, radiothermy, hot baths, electric blankets, and infra red cabinets taught him that these possess inherent hazards. The recognition of this fact prompted him to attempt the development of a relatively safe and simple method for fever induction and mairtenance. A simplified air-conditioned appar tus in which the air temperature, relative humidity, and air velocity are adequately controlled resulted.

Simpson (105), in 1933, reported the early results obtained in the pyretotherapy of neurosyphilis with this new machine. The machine itself consistec of an ultra 
high frequency electric current applied by neans of condenser discharges of a modified short wave radio transmitter, developed by Whitney, Page, and De Walt, in an air conditioned cabinet, developed with the collaboration of $\mathrm{Mr}$. Charles Kettering and Mr. Edwin C. Sittler of the Research Laboratories of the General Lotors Corporation. The purpose of the air conditioned cabinet was to dissipate sweat as it collected on the skin surface and thus to prevent arcing and burning of the skin as the result of concentration of the short radio waves in the drops of sweat.

Soon after this report was made (107), an accidental observation caused an alteration of method of producing and maintaining artificial fever to be brought about. hile subjecting a child with congenital syphilis to artificial fever therapy by the combined radiotherm and air conditioned cabinet method, the nurse technician failed to turn on the switches controlling the out part of the high frequency currents. The rectal temperature reached the desired level of 106 degrees $F$. in the usual leneth of time. It was then discovered that the high frequency currents had not been utilized for fever induction. By adjustment of the air temperature-humidity factors in the air conditioned cabinet the temperature was maintained at this $l \in v \in l$ for the usual five hour period.

This fortunate occurence led to the development of a much simpler, safer, less costly and more easily 
controllable air conditioned apparatus, the Kettering hypertherm.

In the present stage of development (59), the Kettering hypertherm consist of an insulated chamber in which the nude patient lies. This chamber consists of a rectangular box about six feet long, thirty inches high and thirty-six inces wide, mounted horizontally on long legs and divided into two unequal parts: one, the main compartment occupied by the patient, is large enough to accomodate the trunk and extremities; the other is a small, shallow compartment at the foot of the chamber and separated from the main compartment by an asbestos partition in which is a small, open grill. In this smaller copartment is mounted the simple mechanism designed to heat and humidify the air as well as to force it to circulate through the chamber proper. The ceiling of the chamber is double, and the anterior third of the inner layer of the cediling contains a large number of holes, through which the heated and humidified air furnished by the generating apparatus penetrates the main compartment of the chamber and circulates around the patient. The floor of the chamber is also double, and its inner layer constitutes a bed which, moving slowly on brass rollers, can be rolled into the chamber or withorawn from it with little effort. The bed is covered witha comfortable air mattress. The two legs suporting the head end of the chamber are souble, and one set, forming an integral part 
of the rolling bed, is fitted withcasters to facilitate the inward or outward movement of the bed.

At the head end of this bed is a projecting shelf, which remains outside the chamber when it is closed and on which rests the head of the patient. This end of the chamber can be closed by means of a vertical panel which, sliding in metal grooves at each side, can readily be lowered or raised; once closed, this panel is firmly held in place by two large hand screws. One turn of the screws permits the panel to be quickly raised, and the patient can thus be withdrawn from the chamber in five seconds. In the center of the lower border of the vertical panel is a rather large and deep, circular indentation that surrounds the patient's neck. Within this main indentation is fixed a piece of sponge rubber, in which a smaller, secondary indentation fits loosely around the neck.

The side walls and ceiling of the chamber are made of heavy celotex, while the floor is made of wood.

The thermogenic mechanism consists of a small electric air heater, with three units; this is controlled by external switches which makes it possible to use one or all three units, and also by the thermostat which permits one to regulate the temperature of the air within the chamber, and a pan of water heated by two small electric elements, the heating of the water for humidification being regulated by an automatic humidistat or wet- bulb thermostat. 
Dry-bulb and wet-bulb temperatures within the cabinet are indicated on large dials, equipped with warning pilot lights, on the top of the front end of the cabinet where they may be constantly observed by the nurse-technician. The temperature-humidity factors may be controlled by the turning of a single knob. The heated and humidified air is forced by an electric blower between the two layers of the ceiling of the chamber, whence it enters the main compartment through the holes in the anterior portion of the inner layer of the ceiling, circulates around the patient about ten times a minute, and returns to the heating and humudifying mechanism through the grill in the partition that separates the patient from the mechanism.

The average set of air conditions to which the patient's body is subjected is: dry-bulb air temperature of 140 degrees to 150 degrees F. (60-65 C), relative humidity of 35 to 40 per cent, and an air velocity of 425 cubic feet per minute. The elevation of the rectal temperature to 105 degrees F. $(40.6 \mathrm{C}$.) is ordinarily accomplished in forty minutes to an hour. The air is constantly conaitioned by continous passage through the air conditioning compartment. The afety and comfort of the patient are greatly enanced by the accurate control of the relative humidity.

By means of panels sliding in metal grooves at each side it is possible to keep the patient's skin under 
observation, to take the blood pressure, and to take rectal temperature every few minutes.

The mechanism of $f \in v e r$ induction with the Kettering hypertherm depends primarily upon heat transfer by conduction from the circulating heated air and the heated air-mattress. This factor, combined with prevention of the normal rate of heat loss from the body by radiation and evaporation, is responsible for the elevation of the body temperature and its maintencance at any desired level. Fifty-five of these units have been lent to twenty medical research center, strictly for investigative purposes. The physicians and nurses charged with this undertaking receive special training in the Department of Fever Therapy Research a.t Liami Valley Hospital before the apparatus is released. The apparatus is not on the market and because of the danger of unscrupulous exploitation, probably never will be, as far as outright sale is concerned.

A simpler, smaller and less costly apparatus is now being developed and will be ready for use in the near future. It will be ceded on a loan-lease basis to selected institutions.

This ap saratus for producing fever is viewed very favorably by those who have seen it function. Desjardins (31) expresses these advantages over other mechanical forms of inducing pyrexia:

1. Any degree of fever can be attained and 
and maintained for as long as the condition of the patient allows or requires

2. The patient's body is entirely free within the chamber and the apparatus does not involve the use of contact electrodes, condenser plates or other electrical gadgets of any kind

3. Permits the nurse or attending physician to take care of the patient throughout the session of treatment with the greatest ease

4. In case of emergency the chamber can be thrown open and the patient witharawn in a few seconds

5. The patient is usualiy able to return to work on the following day following the treatment, unless the extent of his cisability makes hospitalization desirable.

Hot Noist Air Chamber

Atsatt and Patterson (3) have recently described an apparatus in which hot moist air is used. It consists of two cabinets, constructed of celotex panels. The upper one is suspended from the ceiling by ropes and pulleys-the lower rests on the floor.

The lower cabinet is a box upon whose top the patient lies. There is a marginal grating which allows entrance of hot moist air into the upper cabinet.

The heat is generated by 660 watt coil generators. The moisture is supplied by a full length copper trough 
suspended above the heating elements. Fastened to this trough is an orainary flat coil heater, so that between the rising heat from the coils and the directly applied heat from the flat heater, the water simmers and emanates moisture into the heated and rising air.

The upper cabinet is designed not only to confine the hot moist air which is generated in the box below but has an independent delicate heating system to permit automatic temperature control.

This cabinet is heated by ten sixty watt carbon filament bulbs so connected with a double pole thermo$r \in g u l a t o r$ that the turn of a knob will change the box temperature a fraction of a degree.

The device can be constructed by any competent hospital engineer at a cost considerable under one hunàred dollars.

No clinical reports of this apparatus have been published as $y \in t$.

Conclusion

As it may be seen there are quite a number of methods of producing artificial hyperpyrexia. Although various investigators do not agree on which physical device is superior, they do agree very uniformly that the physical agents are safer and superior to the use of infectious agents or foreign proteins. 
It is pretty well agreed that the electrical methods are superior. Bishop (21) studied in a comparative way three electrical methods of roducing artificial hyperthermia. One was an ordinary high power diathermy machine with a frequency of 1,000 kilocycles and an available current through the patient of from five to six amperes. Another was a radiotherm employing a system of two 500 watt radio transmitting tubes, oscillating in a push-pull Hartley circuit at a frequency of approximately 10,000 kilocycles. The third device was a radiant energy machine consisting of a powerful bulb in reflector, mounted on exterior of the box, the patient being irradiated through holes cut in the flat roof of the cabinet. The conclusions reached were:

1. No difference in clinical effects and results 2. All methods rely on circulation of the blood for redistribution of heat in body from site of application of energy

3. Wile any electricsl method can be wade to work efficiently and safely, the radiant energy methods seem to be the nost convenient and economical.

The Council on Physical Therapy (29) of the American Medical Association carried out a survey over a period of five months to evaluate the efficacy of physical agents. A list of questions were sent physicians who had written articles on the subject of hyperpyrexia or $v \in r e$ is some way 
familiar with the subject. The sources of energy reported as having been tried were oiathermy, radiant energy, hot water baths, and various sources of high frequency current. After a careful study of the survey the council concluded that any type or machine or apparatus may be used with equal success, provided the person in charge is thoroughly compe$t \in n t$.

Thus it may be seen that it does not appear to be a matter of especial importance whet er artificial fever is brought about by hot baths, electric blankets, high frequency currents and short wave raciation or thermostatically controlled radiation, since any and all these measures tend to yield about the same effect. Any of the physical methods in competent hands will be effective. 
TEUPERATURE REGULATION 
The advent into therapeutics of artificial pyrexia brings into prominence the questi n of normal control of body temperature.

Temperature regulation occurs only in those species which have a highly developed nervous system. The existence of a thermostet like nervous mechanism at the base of the brain is indicated by the demonstrations of a number of men.

Ott (92), in 1884, showed that the thermal control centers were situated in the neighborhood of the corpus striatum.

Work of Aronsohm and Sachs, in 1885, seemed to demonstrate that the corpus striatum was the seat of the nervous control.

Qsenschmidt, $\mathbb{K r} \in \mathrm{hl}$ and Schnitzler, in 1914, carried out a number of experiments and concluded the tuber cinerum had much to do with temperature regulation.

Hasma found that stimulation of the base of the brain between the corpora namillaria and a point cephalic to the tuber cinerum produced sweating.

Barbour (7), in 1921, stated that warming of the region of the corpus striatum in rabbits reduces the reatal temperature while cooling has the opposite effect.

Cramer showed, in 1928, that with the exception of respiration, all the factors concerned in the heat regulation of warm blooded animals are under the direct control of sympathetic nervous system and therefore subject to the 
functional activity of the thyroid and adrenel glands. Bince heat regulation is a function of the sympathetic nervous system, the so called heat centers in the tuber cinerum is explicable as a group of nerve cells representing the central connecions of the sympathetic. (13) It has been shown that dehydrating a dog with intravenous injections of concentrated destrose solution produces a very high temperature attributable to concentration of the blood ana lack of water available for giving heat. (4) Keller and Fare (68) reported, in 1931, that the removal of the hypothalamus alone destroys the capacity of cats to control their own temperature.

Bezett (8) and othersseem to verify the work of $\mathrm{K} \in \mathrm{ller}$ and Here when, in 1933, the concluded after much experimentation the presence or absence of temperature control appeared to be associated with the preservation of the hypothalamus just cephalic wo the coroora mammillaria.

So much diversification of experimental results only leads to the conclusion that the exact location of the temperature regulatory center is not known, but that this center is located somewhere in the base of the brain cannot be denied. 
PHYSIOLOGIC REACTION TO FEVER THERAPY 
The use of artificial fever in the treatment of various diseases offers an opportunity to observe some of the specific effects brought about in the human body by changes in temperature alone. Regardless of the method used, whether diathermy, radiothermy, hot baths, or heated cabinets, the resultant hyperthermia is characterized by more or less identical effects.

\section{Blood Flow}

\section{Pulse Rate}

The general observation is that ouring fever therapy there is an increased flow of blood whereby the temperature of different parts of the body is roughly equalized and the heat brought to the surface for dissipation through the skin.

Desjardins (32) stated that the pulse rate increases rapidy at the beginning of each session of treatment; that is, through the ohase of rising temperature. Then the pulse rate tends to stabalize itself, but the level of relative stabilization varies considerably. In some cases the pulse rate increases to 140 to 150 beats a minute and then oscillates at about this level during the remainder of the session. This is commonly seen in the more or less phlegmatic patient whose nervous system is stable. In other cases the pulse rate increases to 140 to 150 beats a minute and becomes stabalized at this level. In such patients the amplitude of ocilllations tends to be grester. If during a 
session of treatment, the pulse rate rises to 160 beats a minute, this is regarded as signal of potential danger. Bazett (9), Bierman 14), and Bishop (20) all report increased pulse rate from 130 to 150 beats per minute. The average increase is from $b$ to 9 degrees per minute for degree Fahrenheit.

Pulse volume changes

osborne and others (0) have cbserved an increased pulse-volume change with all types of artificial $f \in v e r$ except foreign proteins, which gave a primary decrease of the pulse-volume change associated with the chill. They interpreted the increased pulse volume change as increased circulation, a result of the vasodilatation and probably increased cardiac output. The effect of artificial fever on peripheral circulation, when induced by generaly heat with prevention of loss of heat, was about the same with all methods usea. The maximim circulatory response showed marked variations as the temperature was maintained, which they interpretted as due to instability of the vasomotor system and instability of the heat regulating mechanism, which is intimately associated with the vasomotor system. This suggeste that high therapeutic fevers up to $106 \mathrm{~F}$. as often used are too high unless factors other than circulation play a part and are brought out only be fevers above the optimum.

The circulatory response to artificial fever induced 
with foreign protein differed from that obtained with artificial fever induced by external heat. Foreign protein uniformly in five patients gave a primary vasoconstriction associated with the chill and followed by vasodilatation. The vasodilatation was never as great as that produced by the other hethods unless heat loss was prevented by insulating the body and the fever maintained. The fundamental difference in the results of foreign protein fever and that produced by external heat is that the vasodilatation and vasoconstriction of foreign protein therapy is probably of central origin while the vasodilatation of $f \in v \in r s$ proauced by other means is chiefly peripheral in origin.

Circulatory rate

The relationship between body temperature as artificially elevateo with the radiotherm and the circulation ti e has been studied by Kissin and Bierman (61). The methods of determining the time was devised by Robb and weiss and consisted of injection of small doses of sodium cyanide intravenously. They found the circulation time shortened as the body temperature rose, and conversely lengthened as the temperature $f \in I l$. The blood viscosity was increased during hyperpyrexia. The velocity was not always proportional to the temperature nor to the pulse rate but followed the temperature more closely than it did the pulse. On one occas ion an increase of more than 400 per cent in velocity of blood flow was noted. 


\section{Blood pressure}

It is a constant observation among those who engage in fever therapy that there is a rise in blood pressure.

Wiggers and Orias (117) treated dogs mith radiothermy and reported marked increase on systolic pressure. Birman (15), employing the common auscultatory technic, noted that during hyperpyrexia the systolic blood pressure usually showed slight elevation followed by a gradual fall to a point below the original level.

According to Jones (53) the blood pressure response is variable: the pulse is always increased. The systolic pressure usually rises 20 to $30 \mathrm{~mm}$ of mercury at the beginning of the fever, then decline, varying between 80 and $130 \mathrm{~mm}$. The diastolis pressure drops very early after onset of the temperature rise, and usuallr ranges about 50 to $60 \mathrm{~mm}$, though it may drop so low that pulsations are heard at zero

Desjardins (32) observed that the blood pressure rises more rapidly than the temperature. By this is meant that the pressure begins to rise before the temperature, and this advance continues until the temperature has reached the maximal level at which it is to be maintained. This fact may seem anachronistic but is readily explained by the physiological adaptation of the body to any increasein temperature. When the body is subjected to a temperature 
higher than its ordinary temperature, it seeks to dissipate the excess heat. It matters little whether the increase in body heat is brought about by the exposure to external or internal source of heat, because the body can diminish the excess heat only by two principle means: first, cutaneous evaporation through perspiration and pulmonary evaporation through respiration second. Therefore, as soon as the body heat begins to increase, even by one degree, the heart begins to function more and more actively, because the heart is then called on to propel the mass of blood more and more rapidly toward the pulmonary tree and toward the capillary system of the skin. Naturally this demands a greater and greater activity of the heart as the temperature ascends.

The reaction of the blood pressure to heat is a matter of individual variation. By itself, the significance of this variation is slight. What is important to know and to watch attentively is the variability of the pulse pressure of the same patient. This is the most accurate index of the condition of the patient and of his ability to tolerate an increase in temperature.

Blood volume

Opinion of the investigators seems to ciffer concerning a change in blood volume Most men believe that there is very little if any change if the patient is given fluid during the course of the artificial fever. 
Knudson and Schaible (63) in experimenting on dogs found that on producing hyperthermia by means of radiothermy there was a decrease in blood volume amounting in some experiments to 25 per cent. Of course there mas no effort on the part of these workers to supply fluid to the animal during exposure.

Bischoff and others (16) noted increase of $I$ and 2 per cent in blood volume in three case anc decrease of 1 and 4 per cent in two ohers.

Bierman (15) observed that although patients lose large quantities of fluid through the sweat, their weight and blood volume at the end of treatment are about the same as at the beginning if they are permitted to drink as much fluid as they desire.

The opinion of Moen and others (79) differs however. They noted an increased blood volume. That such a change could not be accounted for on the basis of general body dehydration was indicated by experiments in which loss of body weight was prevented by giving of water by stomach and by inhalation of water vapor.

Electrocardiograms

Very little work has been don Wiggers (117) founa no significant changes in electrocardiographic readings in dogs treated with radiothermy until the temperature reached critical heights. The $R-T$ interval was abbreviated and there was a decrease in voltage of the ventricular deflections. 
Viscosity

All the investigators have observed no viscosity changes if large fluid intake is encouraged. Naiz bed capillaries

Tenney (110) made a microscopic study of capillaries of nail bed. These showed an increase in the size and number of capillaries during the height of the temperature.

\section{Blood Cellular Elements}

\section{Erythrocyte count}

Blood counts made during hyperpyrexia invariably show an increase in the hemoglobin and in the red blood corpuscle count. This increase in primarily due to dehydration. However, after finding a number of the younger forms of erythrocytes, $T \in n_{n} y$ (110) concluded that there must be some stimulation of the blood forming organs. Erythrocyte count, sedimentation rate

Tenney (110) and Moen (79) noted a fastex sedimentation time and an increase in the blood plasma. Nicholls and others (89) noted little if any change.

\section{Leucocyte count}

During $f \in v e r$ therapy there is always an increase in leucocytes. Hinsie and Carpenter (48), in 1931, noted while using radiothermy therapy an increase of 75 per cent in leucocytes as well as an increase in staff cells. This increase they believe was due to circulatory stimulation of the bone marrow. The maximum increase came at about the 
ninth hour after treatment, returning to the normal level at about the twentieth hour.

Recently Cohen and Warren (28) to determine the changes occurring in the number of blood cells during artificial treatments, in which the patient's temperature was elevated and maintained at a constant level for a definite period by radiant energy, observeà ten patients during a total of eleven treat ents. Red cell count, hemoglobin, white cell count, and differential count were made. A leucocytosis was found in $\in v \in r y$ case. A relative anc absolute increase of polymorphonuclear leucocytes was observed during or immediately following the febrile period. Ther was a substantial relative and absolute decrease in lymphocytes. There was a slight rise in the red cell count and hemoglobin during or immediately following the period of fever. The observations suggest a mobilization into the circulation of available and nearly mature cells of the myeloid and erythrocytic series as a resilt of $f \in v \in r$, while the cells of the lymphoid series decrease during the period. other men to determine that fever treatments produce leucocytosis characterizea by an increase in percentage of polymorphonuclears at the expense of the lymphocytes are $T \in n n \in y$ (110), Bierman (1E), and Perkins (94). Leucocytes, phagocytosis

Warren and Wilson (113) reported an increased rate of phagocytosis. 


\section{Platelets}

Tenney reported an increase in platelets with a definite increase in the clotting factor.

\section{Blood Chenistry}

Non-nitrogenous elements (urea, uric acid, creatinine), N.P.N.

Karr and Nasset (57) reported in 1934 the urea, amino acid, creatinine, anc uric acid nitrogen fractions of the blood as weIl as the N.P.N. to maintain essentially the same relative concentrations, up to a rectal temperature of 42 to 44 degrees $C$.

Other investigators report results contradictory to those of Karr and Nasset. Jones (b3) observed an increase in blood urea nitrogen of 11 to 14 per cent, in nonprotein nitrogen of 8 to 10 per cent. He believed these changes to be the result of blood concentration through fluid loss, plus the heightened metabolic rate during fever.

Perkins (93) concluded that hyperthermia produces approximately a 10 per cent increase in non-protein nitrogen with a return to the starting point in three to five days. Urea increases approximately 13 per cent and does not return to the starting point as readily as non-protein nitrogen. Creatinine increases 4 per cent, increasing slightly more during the three to five days following treatments. There is no significant change in uric acid. These changes Jones believed represent increased catabolism, which, 
in the average patient, is fairly well compensated, and therefore the changes in blood chemistry do not exceed the so called physiological limits.

Neymarn and Osborne (86) as well as Simpson and Kislig (105) report increase in non-protein nitrogen and creatinine.

Sugar, phosphorous, plasma lipoids, inorganic constituents

Perkins (93) $r$ eported approximately a 20 per cent increase in sugar which returns to the starting figure within three to five days. Simpson (105) likewise reported a slight rise in sugar volume.

Different results were reported by Hopkins (49) who produced febrile reactions by hot baths in twelve young adults with the purpose to determine changes favoring neuromuscular hyperirritability. The peak of the body temperature was selected for investigation and comparison with the normal state of blood chemistry before the bath. whole blood sugar values showed an average fall of 9.45 per cent. Three factors could conceivable have been functioning to lower the blood sugar values: (I) the increased metabolic activity of the fever, (2) the alkalosis and (3) the dilution of the blood.

In regard to phosphorous Bischoff (17) analyzed whole blood inorganic and acid-soluble phosphorous just before heating with high frequency current and at time of maximum temperature. The evioence indicated no change 
in total phosphorous during heating with slight rise in the acid soluble phosphorous.

Some authors have reported lowering of various lipoid constituents of the blood. Wcquarrie and stoesser (71) studied lipoid constituents during fever and concluded that elevated body temperature per se was not responsible for the lovering of the various lipoid constituents.

The inorganic constituents of the blood show rather significant trends. Hopkins (49) reported an average of 4.2 per cent over the control values in the serum inorganic phosphorous. This value assumea some significance when obtained at a time when the blood had undergone measurable dilution. A fall in total serum calcium amounted to 3.3 per cent, and in diffusable calcium to 3.92 per cent. The tendency to attribute importance to the decline in diffusable calcium values, particularly when obtained during the course of developing neuromuscular hyperexcitability. The downward trend in calcium falls in line with the usual catonic changes observed in states of neuromuscular hyperexcitability. The serum sodium content was not appreciably altered, showing an average decrease of 1.14 per cent. Inorganic phosphorous converted to organic

Bischoff (17) subjectea individuals to hyperthermia induced by radio vaves. He found a decrease in rate of urinary phosphorous elimination with increase in metabolism 
and the conversion of inorganic to organic phosphorous in the blood with an alkaline shift of blood pH. This phenomenon had been demonstrated in vitro by Lawaczek in 1924 .

\section{Acid Base equilibrium}

All investigators have found acid base equilibrium to be altered in the direction of slight alkalosis. Bischoff and his coworkers (16) utilizing a radio wave machine produced in three patients a decided increase in the plasma $\mathrm{pH}$ during hyperthermia. Shifts of $\mathrm{pH}$ from 7.47 to 7.59 , from 7.44 to 7.70 and from 7,46 to 7.55 were noted. As the normal range for the plasma $\mathrm{pH}$ is 7.40 to 7.50 , the increases are above the upper limits of normal.

Hopkins (49) found the pH values of the blood rise between 0.02 and 0.16 point, the average in all cases being 0.09 point, indicating a vell defined state of alkalosis. The alkali reserve of the plasma decreased on the average of 9,37 per cent from the original control values.

\section{Proteins}

Hopkins (49) found the serum proteins to increase, even in the presence of measurable degree of dilution of the blood. The globulin fraction increased slightly more than the albumin.

Moen (79), using diathermy over eight to twelve 
hours on dogs found slight anà variable changes were produced in plasma protein fractions. In general, the changes were in the direction of a reduction, but in no case did this reduction attain a statistically significant value.

\section{Chlorides}

Simpson (104) determined that patients subjected to sustained artificial fever for five hours excrete three and four liters of sweat. About 18 to 24 grams of sodium chloride was withorawn from the blood and tissue as a $r \in-$ sult. He believed the loss of chloride produces symptoms of exhaustion.

Kislig and sittler (104) showed that the blood chloride value exhibited an average decline of $40 \mathrm{mgm}$ percent at the end of the febrile period in approximately 80 per cent of patients. In five instances the fall exceeded $100 \mathrm{mg}$; one of these patients developed tyoical hypochloremic tetany during the fifth hour of treatment. Some patients experienced nausea, vomiting, abdominal cramps, or muscular twitchings.

\section{Oxygen content and capacity of venous blood}

Anna Goldfeder (44), In 1933, determined the oxygen in the blood by the Van slyke method. It was found that the oxygen content and the oxygen capacity of the blood, deternined directly after treatment with radiothermy, were greater than before. This may be due to increased concen- 
trations of the blood as a result of excessive perspiration or to a dissociation of the hemoglobin by which oxygen is released.

Bischoff, Ullmann and others (18) determined that in all cases treated with diathermy the hemoglobin of the venous blood was more highly oxygenated following a rise in body temperature. In five cases it was over 95 per cent saturated during the heating.

Carbon dioxide combining power

All investigators have agreed that there is a decrease in blood and plasma carbon dioxice content. Nasset, Bishop and Warren (83) say the lowering of carbon dioxide is to be expected with the extreme hyperventilation noted. The lowered carbon dioxide tension in the tissue which must occur is, likely, a factor in determining the amount of oxygen which can be obtained from the circulatine blood.

\section{Blood Immune Bodies}

There have been only a few immunological studies made of patients treated with hyperpyrexia. Wost workers have limited their investigations to chemical changes.

\section{Agglutinins}

Data on the subject of agglutinins is variable.

Reimann (87) reported that increas $€ \dot{a}$ viscosity of the plasma which occurs during febrile infection as a result of certain plasma proteins enhances the specific 
agglutination power of specific immune serum. Other investigators have shown that agglutination is an important factor in the restriction of bacterial growth and spread in tissue. It is therefore suggested that the plasma protein changes which ocur during infectious disease and enhance agglutination are important factors in the defense mechanism aginst infection.

Ecker and O'Neal (34), however, reported different findings. They induced hy erpyrexia in nine guinea pigs and ten rabbits by means of high frequency electric current. The hyperpyrexia depressed but dia not entirely destroy innoculation agglutinins to B. Typhosus. The amount of depression was roughly proportional to the length of time of heating and the degree of temperature obtained.

\section{Complement}

Ecker reported the complement was usually depressed on first heating but on second was stimulated. Jung and Day (54) demonstrated that no significant changes in the complement content of the serum content wes effected by diathermy and such slight alterations as did occur were probably explainable by normal variations in complement and slight differences in the suspension of blood cells.

Bierman and Fishberg (15) reported temporary dimunition of the complement fixing antibody titer of blood as a result of hyperpyrexia produced by physical means. 


\section{Opsonic index}

Jung (55) reported in only five out of thirty-five tests even a slight increase in opsonic index. She also found that the phagocytic property of leucocytes was virtually within normal limits.

\section{Gastric Secretion}

Gastric analyses, made at thirty minute intervals during the febrile period, indicate that the free hydrochloric acid completely disappears during the first thirty to ninety minutes. The combined acid exhibits a decided, but less complete decline. (55)

\section{Sreat}

Simpson (104) made chemical anelyses of sweat and found an average content of $650 \mathrm{mgm}$ per cent. It was apparent that from 20 to 26 grams of sodium chloride were being withdrawn from the blood and tissues during each treatment.

Bierman believes lactic acid found in sweat acts as a base saving substance and a powerful buffer. The lactic acid content of sweat is increased during hyperpyrexia. (15)

\section{Urine}

Oliguria and anuria are almost invariably sequelae to hyperthermia carried to 42 degrees $c$. or higher. It has been suggested that dehydration and damage to renal peren- 
chyma are important factors in the lose of kidney function. The reaction is unchanged or slightly alkaline.

$$
\text { lietabolic Rate }
$$

The parallelism between fever and variations in the metabolic rate is well known. The major part of the work in this $f i \in I d$ has been one upon patients with febrile diseases such as typhoid and malaria, while little has been done on fever produced by physical means.

In 1931, Nasset, Bishop and Naren (83) induced fever in anesthetized dogs by means of diathermy and found an average increase of about 12.5 per cent in the metabolic rate for each degree of tenperature $C$. rise.

In 1932, Bierman (13) stated the increase in metaboIism follows the temperature lem of Van't Hoff, which means that for $\in$ very rise of 10 degrees $C$., the rate of oxidation is increased 2.5 times.

Neymann and Osborne (87) found an average rise of 7 per cent in the netabolic rate for each degree fever (F) in patients in whom body temperatures was raised by mean of aiathermy current.

Kopp (67), in 1335, studied the metabolic rates of seven male patients having neurosyphilis in whom fever was induced by artificial means. An increase in the metabolic rate occurred when fever was inauced by the combined method of aiathermy current, the electric blanket, light cabinet, and hot moist air. Hetabolic rates from similar 
temperature levels were higher when the te oerature was rising than when faling. There vas little variation from the accepted rise of 7.2 per cent for each degree $F$. The rapidity of the rise in body temperature played no part in the results obtained. Repeated fever treatment of one patient over a period of seven months had no residual effect on the basal metabolism.

\section{Electrocaraiograms}

In general electrocardiograms show the atcrease in voltage of the action currents of the heart consistent with a low blood pressure.

\section{Conclusion}

The benefits of fever therapy presumably arise from:

(1) A direct bacteriolytic or bacteriostatic effect due to the influence of heat itself on bacteria

(2) An inairect becteriolytic or bacteriostatic effect $r \in s u l t i n g$ from increasing formation or mobilization of immune boaies.

(3) A local effect from vasodilatation providing an augmented blood supply to inflemed tissues.

(4) A general effect from the heightened metabolism incident to $f \in v \in r$.

It mast be admitted that the date regaraing all these factors is meager and contrdictory. Until more vork is done, conclusions are somethat presumptous. 
PATHOLOGICAL REAC'IONS 
The raoidly increasing employment of artificial fever has made a recognized denand for knowledge of the physiological and pathological phenomena accomoanying and following it. This is attesteo by a voluminous literature most of which has accumulated ouring the last five years. It would seem, however, that the physiological group of phenomena has been more exhaustively studied than the pathological ones.

Injury by expcsure to heat is by no means new. Osler (91) gives to heat stroke the distinction of being the oldest known disease. Febrile reactions in infections and in other diseases was feared for ages and, even though there has been an increasingly friendiy attitude toward fever on the part of physicians since nelch (115) delivered the Cartwright lectures in 1888 , its potential dangers are still sufficiently obvious. Hall and Wakefield (45) studied dogs placed entirely within a heated and humidified chamber with a wet bulb, between 95 degrees $F$. for periods of from 20 to 75 minutes. Rectal temperatures of 106 degrees to 113 degrees F. were produced. Necropsies revealed left ventricles in systole; generalized venous congestion, most mariced in mucous meinbranes, lungs and liver blanched rigidy contracted intestines; Cilated stomachs; cloudy swelling of kidineys; contracted bladders, and petechial hemorrhages. Nicroscopically there was considerably cellular degenerative changes varying in degree 
and most prominent in lungs, kidneys, liver, intestines, thyroid ana brain, and acute passive congestion in all tissues.

Jacobsen and hesoi (Ez) elevated the temperature of dogs by means of raciothermy over periods of 37 mirutes to thirty hours, twenty minutes, the longest single treatment covering twelve hours. Waximum temperatures of $107 . \mathrm{E}$ to 112.4 degrees $F$. were attained. These authors sumarized their detailed morphological changes as congestion of the organs, peripheral hyperemia, cloudy swelling, fatty degeneration, dehydration, glycogen depletion, focal hemmorrhages, especially in gastro-intestinal tract, epithelial hyperplasia in the parenchymatous organs, stimulation of bone marrow, and following prolonged periods of heating, degenerative lesions in male germinal epithelium.

Baldwin and $N \in l s o n(5)$ exposed rats to high frequency currents for from four to thirty minutes, producing rectal temperatures as high as 113 degrees F. Necropsy finaings included a heart, usually in ciastole, incipient coagulation necrosis of periphery of lungs, heart and liver; spleen choked with degenerating erythrocytes; necrosis of the periphery of liver lobules, extravasation of blood in kidney with dilated glomeruli; capillaries filled with blood; alterea red blood cells; fibrin and cell detritus in Bowman's capsule, and degeneration or exfoliation of the epithelium of the small intestines below the ampulla. of Vater, accompanied by leucocytic infiltration. 
Ealcwin and Dondale (6) repeated the experiments just described with particular attention to the epithelium of the intestinal tract. Regeneration was found to begin soon after the last treatment and to be complete in most instances by the fifth or seventh day.

Wortimer ( 80$)$ heated dogs with both radiothermy and diathermy and found similar histological changes and noted hyperemia and hemorrhages.

The only cases of pathological changes in man from artificial fever are the two cases reported by Hartman and Vajor (46) in 1936. The study consisted of two clinical cases coming to autopsy after fever therapy and of twenty dogs, eighteen of which were subjected to fever of various durations and degrees and two of which were used as controls being given excessive amounts of sodium anytal, a sedative used in all but two of the other experiments and in the human cases. The pathological chenges in both the humen cases and the experimentai animals were engorgement of the blood vessels, especially the capillaries, hemorrhage and degeneration. The most vital changes seen were those in the brain amounting to hemorrhagic encephalitis in some instances, those in the lungs constututing hemorrhagic pneumonia and those in the adrenal characterized by degeneration in the cortex with hemorrhage. Death occurring during or immediately after treatment was cue to vascular collapse. Although the changes describec have been noted in animals receiving morphine alone as a 
sedative, both the human patients and most of the animals received sodium anytal, a drug which in large amounts is known to produce congestion and even capillary damage, especially in the brain. Since both the fever therapy and sodium amytal tend to produce marked dilatation and engorgement of blooa $v \in s s \in l s$, it is sugesested that the combination should not be usea in patients. 
CONPLICATIUN AND CONRAINDICATION 
Subritting a patient to therapeutic fever is considered by all the workers in the field to be a major therapeutic measure. Certain dangers exist at all times, and there are a number of absolute contrainaications to the use of such neasures.

Kobak (65) expressed the opinion of all connected With the menzgement of fever therapy when he says, "It hardly needs pointing out that where one employs methods so critical, one comes close to stretching vital activity to the breaking point. Hyperpyrexia may be likened to surgery, with its potential dangers and spectacular recoveries. It is thus a procedure only to be enoloyed when other measures have been tried and found to be inffective. Bazett (10) has made a detailed study of the effect of and the dangers connected with artificial pyrexia. He concluded that the dangers connected with it appear to lie in three directions. These are: (1) Too high a brain temperature, (2) a marked hypernea reaction with lowered carbon dioxice tension and alkalosis. The body's automatic compensation for this circulatory state is the creation of more acid blood by increase in the temperature which is followed by alkalinization., (3) dessication through the loss of fluid in sweat, and circulatory failure through insufficient filling of the heart.

The first of these may be combatted by cooling the head, providing a rise in brain temperature is not a necess- 
ary part of the treatment. The hair makes a good insulation. Probably a constant stream of moderately cold water applied to head and neck and scalp would be beneficial.

The second danger may be avoided in most subjects if the rate of heating is kept slow, for the hypernea is more related to the rate of rise of body temperature than the actual temperature reached. But as it occurs and seems to be a serious factor, the administration of a gas mixture containing carbon dioxide will immensely improve the condition and confort of the patient.

The third danger may be avoided by forcing fluid intake. Since the loss of sweat implies the loss of an approximately 2 per cent solution of salt, it has been found that in all such exposures to heat much better results are obtained if the subject substitues for water a 0.2 per cent solution of common salt.

In all conditions of extreme pyrexia the condition of the circulation must always be borne in mind, for cooling can be carried through successfully only as long as the circulation remains in good condition.

When artificial fever therapy became so prominent it was realized that undoubtedly certain diseases or physical states preclude the use of high fever therapy. In 1934 the Council on Physical Therapy of the American Wedical Association (29) published a number of contraindica- 
tions. Artificial fever therapy should $n \in v \in r$ be used in advanced age, usually considered as over sixty, in cardiac or renal insufficiency, rheumatic endocarditis, aortic aneurysm, advanced arteriosclerosis, pulmonary tuberculosis, diabetes, or late neglected neurosyphilis that has progressed to complete dementia. As further precaution against failure the Council also advocated that every patient undergo a thorough physical examination and clinical investigation, these to include electrocardiograms, sedimentation and coagulation time, and all established tests employed in study of syphilitic patients. The Council believed this therapy should be used in hospitals surrounded with safeguards commonly employed in a najor surgical operation and under the direction of skilled physicians. The assisting technician should have ample training and experience and be capable of recognizing untoward symptoms and know ways of avoiding dangers .

Certain complications may develop in a course of fever therapy. occassionally cutaneous vesicles develop while the temperature is being maintained at a high level (106 to 107 degrees F.). Most common places are on the legs, and, in women, about the breasts. Popp (96) at the Mayo Clinic has found that if first treatment is given cautiously and not too much emphasis placed on maintaining a high temperature, this complication can be avoided 
fairly easily. It appears that if the sudiferous mechanism and collateral circulation are suitable adapted, cutaneous complications do not arise.

Another distressing complication is nausea accompanied by vomiting which occurs toward the end of the session of fever. The discreeable condition ordinarily passes after one attack of vomiting and a series of eructations. This complication can be terminated promptly by intravenous injection of 500 to $1000 \mathrm{c.c}$. of fluid, usually 10 per cent solution of glucose.

Herpes has developed about the lips of a fair percentage of patients. No untoward effects result.

In a very small per centage of cases tetany has developed in the early part of treatment. This is probably to be explained on the basis of over ventilation with a resulting acioosis. This condition is overcome promptly by use of calcium luconate intramuscularly or intravenously or by inhalations of carbon dioxide. 
TECHNICAL CONOIDERATIONS 
The technic of the treatment varies in different diseases treated and with the type of apparatus used. However, there are certain general principles to be kept in mind no matter for what the treatment is being employed.

The patient is at first subitted to a general examination in order to eliminate those whose cardiovascular or renal condition might contraindicate fever therapy. In those cases in which the clinician may be slightly uncertain, electrocardiography and a functional examination of the vessels may serve to clarify the situation. When the temperature passes between 102.2 to 104 degrees $F$. there is often a period of mild excitement. If the patient is nervous, pentobarbital sodium or codein may be administered. Electric fans blow air around the head. The technician passes over the head and face towels dipped in ice water. When the temperature is between 105 and 107 degrees F., certain nervous patients show a certain degree of excitement. Usually codeine or sodium amytal suffices to quiet them. However, there is a disagreement among workers concerning which omug is the best. Jones (53) recommends morphine sulphate in one-sixth or a quarter grain doses. Sometimes he reenforces this with scopalamine $1 / 160$ th to $1 / 120$ th grain when a rapid rise and prolongation of the fever is desired. He claims this drug blocks heat loss through formation of sweat and evaporation. 
The disadvantage of scopalamine in the occurrence of abnormal reactions, either too deep a sedation with depression of the respiratory center or stimulation and a mark$\epsilon d$ delerium.

Atsatt (2) reports, "The whole gamut of sedatives, hypnotics and narcotics have been tried. Pure sedation is not sufficient to make the patient comfortable. Drugs which include hypnotic action were often found to cause gastric distress when given during fever. Morphine often depressed the respiratory center to a considerable degree, especially during the height of the temperature elevation even to the point where prolonged periods of apnea were produced. An additional disadvantage under diathermy was the danger of burns developing during deep narcosis"!

out of a long list of drugs that have been tried it has seemed that dilaudid grain 1.32 with scopalamine $1 / 100$ th grain was the most efficient for the initial medication with a repeating dose of dilaudid 1/32nd grain as needed.

Bishop, Forton and Warren (20) tried many sedatives but none seemed well suited for general use. All have some disadvantage, the chief of which is the period of excitement produced by the drug before the narcotic stage is $\mathbf{r}$ ached. Nearly all depressants of the respiration or blood pressure or both. Chloral hydrate in doses up to narcosis point have been effective. 
Techincal Considerations

Just as effective and important is the influence of the technician, who knowing he $r$ patient, reads, tells stories or allows him to sleep accorcing to psychological indications.

The condition of the skin is frequently observed and if any areas of erythema appear, it is first covered with a towel. If this is not sufficient, the erythematous area is covered with a piece of ice for fifteen to thirty minutes.

Between 11:30 A.M. and I P.M. many patients exhibit mild degree of agitation. This is probably due to the habit of the stomach being fed at this hour.

Temperature must not be allowed to rise too rapidly or the skin may not have time to adapt itself. In a few cases in which the skin is exceptionally sensitive, it is sometimes necessary to bandage the extremities. Because of the tendency of heat to concentrate on small parts, the skin of the extremities usually is more sensitive than that of the trunk. The skin of the female is also more sensitive than that of the male.

At the first session of treatment it is unwise to allow the temperature to rise above 106.5 degrees $F$. at any time. Not only the skin but the heart and lungs and blood vessels should be given a chance to adapt themselves to the treatment. The first session should always be regarded as a test session, and the ability of the patient's 
cardiovascular, respiratory and cutaneous syste, to tolerate a high temperature should be closely observed. Food is not permitted during treatment, but as soon as a session has been completed and the patient's temperature has returned to normal, the patient may have as much milk as he desires.

Fluid intake is important, the amount depending on the type of case, averaging about $50 \mathrm{c.c}$. Every twenty minutes. Two drams of mixed salts are supplied.

Temperature should be recorded every fifteen minutes, every five minutes during the height of the fever. The first temperatures were taken orally. These were found to be unreliable as the fever progressed because of mouth breathing and the frequenct administration of water. Axillary $\epsilon$ timations were then tried and were scientifically satisfactory but disturbing to the patient and awkwrk to take.

The most efficient and accurate method is that which is now used generally. An electric pyrometer energized by the ordinary house current is connected to a sensitive thermocouple which is inserted into the rectum. The olive shaped device is self restraining. The temperature is read directly on a large scale and is accurate to two-tenths of a degree.

Desjardins tried out various electric thermometers but found them to have an appreciable and disconcerting 
lag. He prefers an ordinary thermometer because of greater reliability and the opportunity it gives the technician to watch the patient.

Pulse and respiration are recorded every twenty minutes.

If nausea and vomiting occur despite going without breakfast, 500 to $1,000 \mathrm{c.c}$. solution containing 10 per cent of dextrose and 1 per cent of sodium chloride may be injected into the vein.

Ice compresses over the heart and in the axilla are often used to slow down an advancing pulse rate. Evidence of impending circulatory collapse such as rapidly increasing pulse rate, intense facial cyanosis or marked fall in blood pressure call for immediate termination of treatment.

For a pyrexia whose function is elimination or a change in metabolic rate or circulation and where avoidance of fatigue is a factor, it is felt that a temperature of 101 degrees $F$. held not over one-half hour is sufficient.

The moderate hyperpyrexia for the usual gonococcal infection usually has 104 to 104.5 degrees F. as maximum and is held there for three hours.

The higher hyperpyrexia for luetic infections usually are set for 105 or 106 degrees F. with duration of five hours at that level.

The majority of patients tolerate the treatment quite well, and their behavior is a faithful reflection 
of the character and tempersment of the individual. The poisea person, who is aetermined to get well, behaves accordingly. Some hurn, sing, smoke, or amuse themselves by teasing the technician. Some remain quiet and sleep most of the time. Others, with less will power or whose nervous system is less stable, complain more or less. Certain nervous individuals bef to be released from chamber long before the session is ended.

The duration of the session varies according to the disease being treated. They average from six to ten hours. Aft $\in \mathbf{r}$ the treatment an enema hastens the cooling process.

The patiendt does not leave the treatment room until temperature is normal. Give cold dluid restricted to 1,000 c.c. to prevent voniting. Cold ginger ale probably because of its sugar and alkaline content, is well tolerated. General reaction of patients can be improved by close attention to many small details. The room should be darkened. All noise shoulà be elininated as much as possible.

At the end of treatment the patient should be lifted into bed and not allowed to move suddenly lest vomiting occur. 
DISEASES TREATED 
Some interesting observations on the effect of fever temperatures on gonorrhea have been reported in the literature. Finger, Ghon and Schlagenhaufer stated in 1894 that they failed to produce an urethritis in man by injecting the gonococcus into the urethra of a patient with a fever of 39 degrees to 40 degrees $C$. However, they were always successful if the host was afebrile. Guiard, in 1894, observed a patient with gonorrheal infection who was cured after an attack of scarlet $f \in v \in r$. Neisser and scholtz stated that it was always more difficult to obtain a culture of the gonococcus from patients when they had a fever than when they were afebrile.

Prectically all bacteriologists consider that 37 degrees $C$ is the most suitable tempereture for the isolation and cultivation of iv. gonorrhae and that temperatures above 38 degree $c$. definitely injure the organism. Experiments had proven the injurious effect of temperatures on gonococcus in vitro, but it remained for Carpenter and Boak (22) to establish the thermal death time in vivo. They found that at 39 degrees $C$. there was little if any effect on the groath of the organism. At 40 degrees $C$. about 99.7 per cent of the organism were killed by ten hours exposure. At 41 degrees C., 99 per cent of the gonococci were destroyed in from four to five hours exposure. At 41.5 degrees and 42 degrees $C, 99$ per cent were rendered non-viable in two hours. They concluded that the in 
vivo thermal death time of $N$. gonorrheat is short enough at $41,41.5$ and 42 degrees $C$. to suggest artificially inauced $f \in v e r$ as a valuable aid in treatment of aisease due to the organism. It is doubtful whether complete sterilization by heat can be obtained always from a single artificially induced fever of five hours' duration.

It is to these thorough investigations of Carpenter, Boak, Mucci and warren that we owe the possibility of rapidy curing gonococcus infection. At present the gonococcus is the only micro-organis of which the lethal temperature has been determined and which can be tolerated by human beings. It is possible that the future may furnish equally favoraio date on either bacteria; in this event the field of therapeutic hyperpyrexia will be correspondingly extended. By this it is not intended to imoly that fever therapy has no basis other than a knowledge of temperature necessary to destroy other bacteria effectively and cure other diseases, but in those other cases we must depend on indirect effect of heat, while in gonococcus infection the cure is mainly, if not wholly, a question of degree of temperature ana duration of temperature; consequently the principal, and perhaps the entire, effect is direct and specific.

Between Dec. 1, 1933 and August 1,1935. ninety-two patients with simple or complicated gonococcic infection were referred to Desjardins, stuhler and Popp (32) at the 
Wayo Clinic for fever therapy. Sixteen did not $r \in c \in i v e$ complete treatment because of failure to cooperate. of the seventy-six patients who faithfully completed the treatment, sixty-eight ( 89.5 per cent) were cured and the codition of seven ( 9.2 per cent) improved. In only one patient did the infection prove rebellious to treatment. These results would have oeen even better had certain defects in apparatus been discoverea and renedied earlier.

The patients averaged six sessions for each patient. In fifty-eight cases an average of five sessions of treatment was required to cure the disease permanently. one patients was curea from a single session.

of the seventy-six patients who completed the treatment, fifty-three were males and twenty-three females. The shortest duration of the infection in any case had been three days, the longest six years, an average duration of five months.

In thirty-six cases the gonococcic infection was confined to the urethra, while in fifty cases, various complications existed. Five patients hed associated pelvic infection. Twelve had associated prostatitis, seventeen had gonococcic arthritis as vell as urethritis, three had infection of Bartholin's glands, two had epididymitis, one had seminal vesiculitis, four had urethral sinuses, one had periurethritis, one had infection of skene's gland, one had prostatic abscess, one had periurethral abscess, 
one had pyelitis, two had cystitis, and one had ureteritis.

With improved technique and experience Desjardins concluded it is safe to assume that betwe $\in \mathrm{n} 90$ and 95 per cent of patients can be cured.

Stuhler (109) was moved to say, "I believe that the introduction of fever therapy for gonococcal infection is one of the greatest advances made in the last fifty years. I believe it is of even greater importance to the clinician than was the discovery of the gonococcus by ive isser in 1873 !

Kendell, webb and Simpson (59) at Miami Valley hospital have treated sixty-five patients suffering from simple urethritis or complicated by cervicitis, salpingitis, optralmia. The report is not yet available, but the workers have stated that the results are pratically identical with those of Desjardins, Stuhler, and Popp at Hayo's clinic. 
In 1932 a thirty-nine year old man was referred for fever therapy to Kendell, Webb and Simpson at miami Valley hospital. The patient was suffering from a resistant sero positive syphilis, Findines revealed the patient had chronic gonorrheal arthritis of the wrist of five months duration. Gram negative intracellular diplococci were found in urethral smears. After three five hour 105 degrees F. fever treatments, all evidence of active gonorrheal arthritis disappeared. The joint function which had been practically nil was restored to 90 per cent of normal.

Encouraged by this coincidental observation they decided to treat other cases of gonorrheal arthritis. They have now completed the course of fever therapy of thirty patients with gonorrheal arthritis.

For practical purposes they found that four or five treatments, each of five to seven hours' duration, at a temperature range of 108 degrees to 106.8 degrees $F$. at intervals of three to five days vere productive of prompt and satisfactory results. Fewer treatments were required if interval between treetments was shortened. of the thirty-one patients, twenty-three has positive urethral smears. All others vere reported to have had positive smears previous to admission.

of nineteen patients with acute gonorrheal arthritis the average improvement in point of function immediate- 
Iy after the conclusion of the course of fever therapy was 99.6 per cent; in three patients the restoration of joint function was complete. The ultimate average improvement in joint function in the cases of acute gonorrheal arthritis was 98.4 per cent. Thirteen pairents obtained complete restoration of joint function. of the twelve patients with chronic gonorrheal arthritis the average improvement in joint function at the conclusion of the course was 62.5 per cent; in four patients joint function was completely restored. The ultimate improvement in joint function in the case of chronic gonorrheal arthritis was 88.3 per cent. At the conclusion of the course of fever therapy gonococci had disappeared from the smears of the genito-urinary tract of twenty-four patients. The smears of four patients became negative within two weeks after the last treatment. Supplemental treatment eliminated all evidence of gonococcal infection of the genito-urinary tract of the remaining three patients.

Hench, Slocumb and Popp (47) treated sixteen patients suffering from gonorrheal arthritis utilizing the Kettering hypertherm. Nine of the patients had acute arthritis, while seven had the disease in a chronic form. 88 per cent of the patients with acute gonorrheal arthritis were promptly curea, or practically so, while the remaining twelve per cent obtained marked improvement. of the seven patients with chronic gonorrheal arthritis, all 
but one was markedly improved. The author states, "In gonorrheal arthritis, results are so striking and apparently so superior to those obtained by other methods that we can prescribe fever therapy as the method of choice with considerable assurance!

Other men have had uniformly good results although they have treated only a few patients. Simpson (106) has reported "results uniformly successful in acute cases" Tenney (110) comments, "Radiothermy acts almost as specific! Bishop, Horton and Warren report "results very encouraging. Joints become painless"!

Desjardins (32) expressed the opinion of all workers when he said, "The rapiaity with which, in a large proportion of cases, the clinical manifestation of gonococcic arthritis subsides as a result of fever therapy is astonishing. In the course of the first session of treatment the pain abates rapidly and the swelling diminishes a little more slowly. When the articular inflammation is acute, the effect of fever therapy sometimes is really spectacular. In most cases thorough treatment is followed by complete and permanent resolution of the inflammatory process. When the inflammation is chronic, the clinical manifestations usually abate promptly and the infection is cured! 
The results of fever therapy for chronic infectious arthritis were reported by Larkson and osborne (72) in 1931. Since then fifteen $r \in$ ports by $t \in n$ groups of workers on experience with fever therapy in chronic arthritis have apoeared.

Each worker has, in general, treated only a few patients, only two of the fifteen $r \in$ ports being concerned with more than twenty patients.

Cures were obtained by $T \in n n e y$ (110) in 25 percent of sixteen cases, by Berris (9) in 18 percent of eleven, and by Markson and osborne (10) in 21 percent of nineteen. It would appear that from 25 to 50 percent of the patients in the various series received only moderate relief, ana that no relief was obtained in from 13 to 37 per cent of cases reported by some, and in from 50 to 75 per cent of cases reported by others.

Particular attention shoula be given to the large series of Kohn and Warren (66). They subjected to one or two treatments forty-three patients in the main with purely atrophic, proliferative, and some mixed types, in various stages of disability, deformity and chronicity. In thirtyfive cases all but two patients' pain rapialy diminished and mobility of joint increased. Relapses occurred at end of 12,20 and 24 months respectively in three patients, in whom another treatment was succeseful in giving relief.

cecil has found results frankly disappointing. 
Hench summarized all reports as follows: Approximately 10 percent became symptom free, about 25 percent were markedy relieved, and about 30 percent received no benefit.

Although results have not been as encouraging as in gonorrheal arthritis, it must be remembered the cause is not yet definitely established. Until information is available concerning thermal death time of the various arthropic streptococci under suspicion, the dosage of fever is only guesswork, and naturally perfect results cannot be expected. 
According to Bassoa, between 1860 and 1870, Dr. Rsenblum of odessa inoculated the organisms of relapsing fever, malaria and typhoid into patients with dementia paralytica. In 1876, he wrote an account of this and published it in Odessa County Bulletin. This was emphasized again by agner-Jauregg, in 1877 and 1889. He attempted to use tuberculin, erysipelas, polyvalent typhus vaccine. These produced fair results. An early published prophesy of the therapeutic value of fever on syphilis was that of phillips, who, in 1884, wrote, "Finally it is when we are called upon to treat the more chronic forms of syphilitic disease that we are enabled to appreciate the immediate advant age of uniting these powerful constitutional agents (artificial fever and chemotherapy) for good.

Wagner- Jauregg's first at empt with use of malaria was made in 1917 when he innoculated nine patients. Fair results were obtained. The first report of the therapeutic value of malaria in syphilis was made in this country by Lewis and Hubbard and Dyer (70) in 1934. Since tha a great many reports have been made and there is uniform agreement that between 30 to 50 per cent of case of paresis treated with malaria show remissions. Today physical means are supplanting malaria innoculations for the therapeutic development of fever because of the advantage of the formers. 
Influence of heat on Spirochaeta Pallida.

There is a rapidly accumulating mass of experimental data which provides strong evidence of the unfavorable influence of high body teinperature on spirochaeta pallida. Many observes have reported their inability to find the Soirochetes in the brain tissue of patients who have die following malarial therapy.

In 1919, Weichbrodt and Jahnel placed rabbits with scrotal chancres in a thermostatically controlled incubator with the air temperature at 105.8 degrees $F$. The rabbits were subjected to treatments for thirty minutes once or twice a day. After the second day the spirochetes gradually lost their mobility, declined in number and disappeared. The chancres healed much more rapidy than in untreated rabbits.

Schamberg (99) found that multiple hot baths exerted a favorable influence on syphilis of rabbits and hurnan beings.

Bessemans of thent made valuable studied which demonstrate the feeble thermo-resistance of spirochaeta pallida. He showed that primary syphilis was cured by local or general balneothermo-therapy when the tissues temperature of the chancres was sustained at 104 degrees F. for two hours at $102.6 \mathrm{~F}$. for one hour.

The important research of Carpenter, Boak and

Warren (23) again emphasizes the thermolability of the 
Spirochaeta pallida and suggest the practicability of fever therapy in the treatment of acute as well as chronic syphilis in man. Utilizing heat produced by short wave radio waves of an ultra high frequency oscillator they were able to prevent the development of chancres in twenty-one of twenty-five rabbits when treatments were begun four, five and seven days after inoculation. They also found that multiple unsustained fevers of from 105. 8 to 107.6 degrees F. destroyed Spirocaeta pallida in rabbits with active syphilitic lesions. It was also found that one febrile period of six hours at a temperature of 106.7 to 17.6 degrees F. was sufficient to destroy Spirochaeta pallida

These findings have been confirmed by simpson.

\section{Early Syphilis}

It is conceivable that the same uniformity in results might not ootain following the application of fever therapy to human beings. Syphilis in rabbits pursues a somewhat milder course. Nevertheless, these experimental studies provide incontrovertible evidence of the spirochetoidal effect of sustained high body temperature. Many observers are convinced that fever therapy is capable of producing a distinctly favorable influence on the progrees of early syphilis, particularly when fever therapy is combined with orthodox chemotherapy. This belief was early most prevalent anong foreign investigators. Kyrle 
in 1924, gave 232 serpositive patients with early syphiIis, a course of arsphenamine therapy followed by malaria therapy. Blood serological reactions were favorably influenced in 230 . There have been no relapses since.

In the introduction to the Hatuschka-Rosner monograph, in 1927, Finger says, "The results are significant. They show that in the early period of syphilis nothing influences the serum and spinal fluid reactions so favorably as conbined malaria arsphenamine therapy"

Richet and Dublineau, 1933, after experimentation with animals and humen subjects, concluaed that early syphilis may be cured more rapidly and more certainly by fever and chemotherapy than with chemotherapy alone. Extensive cooporation clinical studies by Stokes, Cole, Noore, o'Leary, Hile, Clerk, Parran and Usilton have led these to conclude that the best results are obtained when combined $f \in v \in r$ and chemotherapy are applied early in the disease.

With the bope that the disastrous late neurologic and $v$ isceral manifestations of the disease might be prevented, simpson (107) subjectea twenty-six patients with primary syphilis to the combined fever and chemothere regime. The cutaneous manifestations of the aisease, including chancres responded with surprising promptness. The Kahn and Kolmer serological reactions were reversed to negative in fourteen, became less positive in the others and gradually declined in intensity. 
There has been no evidence of clinical or serological relapse in the patients treatea with combined fever and chemotherapy.

In thirty-one of thirty-three cases of early syphilis, or 90 per cent, the dark fif 10 examination was rendered negative for spirochaete pallida by hyperpyrexia alone according to Estein. (38)

Neurosyphilis - Dementia Faralytica

Simpson (107) treated twenty patients with a course of fifty hours of fever therapy in the Kettering hypertherm plus thirty injections of chemotherapy. Twelve experienced complete clinical remission; two were restored to a morking status. Four patients were accorded 50 per cent clinical improvernents: two were regarded as having 25 per cent improvement. No relapses have occurred. iveymann and osborne (84) reported twenty-five cases treated in which 64 per cent made a complete sociel adjustment. 8 per cent made a partial adjustment and seven patients were improveá. Neymenn believes with selected material and long periods of $f \in v \in r$ treatment, 35 per cent remissions should be obtained.

Wilgus and Lurie (118) treated ninety-seven cases by diathermy. Forty-five were much improved, seventeen slightly and twenty-three unimproved.

Twelve patients were treated by King and Cocke (60) by means of aiathermy. Eight shoved definite improvement. 
Two made clinical remissions.

Wenninger and Fellows (75) produced fever by diathermy in generaly paralys is and tabes dorsalis in 1931. They concluded diatherny to the the most effective and safe measure for the treatment of paresis and tabes.

Schamberg and Butterworth (100) reported in nine paretics treated with diathermy six improved, three of whom returned to their former occupations.

Jones (53) reported out of fourteen cases treated, five complete remissions, three markedy improved and under home care, two improved in memory and orientation, four no improvenent.

In 1932 four baly disoriented and degenerated paretic were treated by Bishop, Horton and werren (20) by diathermy. All showed great clinical and psychic improvement. All were paroled and only one relapsed. The colloidal gold curves, the protein and the number of cells in the spinal fluid returned to normal. Wassermans in spinal fluid and blood did not become negative.

There are some men still using maleria in the treatment of paresis. At the Fifth Annua Fever Conference helf at Layton, Ohio, 1935, Dr A. B. Bennet in discussing the papers of Ers. Ebaugh, Barnacle and Ewalt said," I am not certain that I understood correctly, but it seemed to me they stated that the malaria mortality was around 24 per cent of Eroup of advancea paretics 
and cerebral syphilis, and eleven per cent of these died within a year. This is the lig thing that has made me feel that malaria is or its way out so far as $f$ ever therapy is concerned!

A survey was recently made at the State Psychopathic institute and he igin state hospital of 300 patients treated with electric blaniet over a five year period. 73 per cent were definitely improved. 10 per cent remained stationary, 7 per cent deteriated, 11 per cent died.

\section{Tabes Dorsalis}

Simpson (107) treated ten patients who had received chemotherapy previously. Ataxia, in nine, and lancinating pain or gastric crisis in all were the chief symptoms. Two patients with ataxia of three months duration in onse case, and of two years' duration in another were restored to normal gait. Six patients obtained some improvement in gait while two showed no change.

The root peins were abolished in all. Recurrence of pains occurred in one patient after the usual course of treatment. This was controlled by adaitional treatments. Normal functions were restored in one case of so called cord bladder.

The Kahn and Kolmer were reversed to negative in four patients, became less positive in three, remained negative in one and remained positive in two 
The spinal fluid reactions were reversed to negative in two, became less positive in three, remained positive in four and became ore positive in one.

Neyman and Osborne (86) treated six tabetics and noted a decided improvement in every case. Lightning pains and cresis ceased after five or six hyperthermic sessions. The gait became less ataxic, and one patient was so much improved thet it was no longer possible to make a diagnosis if tabes. Spinal fluid became negative in this one. In the other five there was a reduction of cell count, a decrease of globulin content and of luetic zone colloidal gold curve.

Tabetic form of Dementia Paralytica Simpson (107) subjected seven patients to combined treatment. One had malaria therapy followed by remission previous to treatment. All had received chemotherapy. Improvement in mental orientation occurred in six. One demented patient showed no improvement and died seven months after treatment. Subsidence of root pain occurred in all. Improvernent in gait occurred in two of the five patients with etaxia. One patient who had had a tabetic gait regained normal gait. One patient with a "cord blacider" regained normal control of bladder function.

The Kahn and Kolmer were reversed to negative in two, became less positive in one, remained negative in three 
remained positive in one. The spinal fluia Kahn and Kolmer were reversed to negative in four, became less positive in one, remained positive in tro.

Diffuse Central Nervous system Syphilis

Simpson (107) treated thirteen patients which could not be classified. Six patients of congenital syphilis. Secen cases of acquired syphilis; nine cases had occular symptoms. Symptomatic remissions occurred in nine of the thirteen, modercte improvement in three, none in one.

The Kahn and Kolmer were reversed to negative in one, became less positive ir seven, remained positive in four, more positive in one.

The spinal fluid reversed to negative in five, remaineo negative in seven, remained positive in one. 
In the past four years three groups rorking independently of each other in the Unites States and one in Europe began applying electropyrexia to the treatment of bronchial asthma.

The treatment of bronchial asthma by electropyrexia was first reported by Fishber osborne and Afremow, in 1931 (39). Seventeen patients suffering from intractable asthma who had proven to be refractive to conventional treatment were given artificial fever by diathermy. Their theoretical basis for employing this measure, according to their opening paragraph, was the clinical observation of temporary relief from asthmatic attacks asoociated with febrile infections. In some instances, the symptoms were completely reversed, in others there was amelioration.

These workers (40) made a further report simultaneously with Miller and Piness(78) and Leopold and Stewart (69). Their final report has since appeared in thirty-seven cases (41). In this final report their laboratory data included weight, blood pressure, vital capacity, results of urinalysis, complete blood count and the chemical composition of the blood, particularly the acid base equilibrium, non-protein nitrogen and urea nitrogen.

The reasoning of Miller and Piness in employing hyperpyrexia was based upon, first, the fact that as tham tics experienced relief following bouts of fever and, secondly, 
that parenteral administration of non-specific protein frequently gave periods of relief. Their conclusions were that there was slight improvement.

Leopold and Stewart quote Chapman as making the observation the observation 150 years ago that asthma was often relieved following active malarial infection. One of seven patients treated by Leopold and stewart by diathermy had fewer attacks. The remaining obtained neither subjective or objective relief. The authors admit technical inexperience and udue concern for the patients .

Phillips and Shinkany (95) have recently reported fifty cases in which hyperpyrexia was used in asthma. They reason from a different theoretical basis. They believe a typical asthmatic is an individual whose general metabolism, circulation and well being are at a low ebb. They reason that if it were possible to raise the general metabolism and increase circulation of organs of internal secretion, an improvement in terminal symptoms might result.

They reported improvement in general metabolism following treatments. The clinical results indicated 82 per cent received definite benefit. Biochenical and laboratory studies, however, indicated that over 40 per cent of these were porribly only temporarily relieved. After six months observation 32 per cent seemea to have 
lasting relief.

These workers emphasize that they do not consider it possible to evaluate any therapeutic procedure applie to bronchial asthma for permenent relief until cases have been observed free from attocks over a period of at least one year. Another report will be made after eighteen months have elapsea. This will be in February, 1937. It must be concluded from the clinical data at present that hyperthermia is not very satisfactory in the treatment of asthma. 
Schmidt (103) was the first in this country to treat multiple sclerosis by artificial fever. He treated in 1933, seventy-seven cases with the hyperpyrexator, a machine in which the fever is brought on by vapor heat developed by infra red element under a tank of water. His report is not very complete. He concluded that cases treated early show best results, those of long auration, showing marked degeneration of the nervous system, offered very little hope of improvement.

In 1934, Neymann and Osborne (88) reported the treatment of twenty-five cases of multiple sclerosis. The material was divided into three groups, mild, advanced and far advanced.

The mild cases could all walk, but showed many of the major symptoms of the syndrome. All four improved to a point where clinical diagnosis mithout history would be difficult. Tro patients retained a positive Babinski on one side. One showed reduced vision, temporal pallor of the disks and positive Barany tests. One was free from symptoms. All returned to work.

The next group of eleven were hospitalized. The major symptoms of the disease were outspoken and tissue destruction was evidently present. After treatment two attained a normal gait. The other nine all showed improvement in gait. About two-thirds of their initial symptoms 
were absent or improved. Four were ale to $r \in t u r n$ to their occupation. Seven livea at home. All were satisfied with their progress and are willing to submit to further treatment.

The far advanced cases of which there were ten were decidedly less benefitted. Six were bedridden when treatment began. one $r \in g a i n \in d$ ability to walk, another with complete quadriplegia regained the function of his arms. Four others were somewhat relieved.

Neymann and osborne concluded that those treated early show best results. It is a well known fact that multiple sclerosis is a disease which has a natural remission rate of about 40 per cent. However, the authors feel that the results cannot be accoubted for by this natural tendency as these occurred with too great regularity in conjunction with the treatment.

Weiss (114) has recently reported on 144 cases treated over a period of four years. Some of these are cases treated in 1933 by schmidt. The machine used is called a hydroenicator, a cabinet like arrangement in which the patient is inserted, and $f \in v e r$ is produced by $\varepsilon$ fine spray of hot water. The outstanding feature was the improvement in motor power and the spastic condition of the lower limbs, which occurrea in 75 per cent of cases. The incoordination of gait and station showed improvement in 35 per cent of cases. Ankle clonus disappeared in 42 
the Babinski sign in 18 per cent, ond sphincter disturcance were benefitted in 25 per cent. The temporal pallor of the aisc cleared up in 10 er cent of cases, while nystagmus showed no evidence of change.

Weiss believed the mechanism was increase in metabolic process with formation of antibodies with neutralization of the toxins.

Cases of long standing with progresssion of disease and no history of intervening spontaneous remissions yielded no results. 
Ophthalmologists for over twenty years heve used non-specific proteins in the treatment of certain eye diseases. The height of the fever produced has served, at least in part, as a guide to the degree of reaction. Whitney (116) has used the Kettering hyoertherm to treat eight cases of varying types of corneal ulcer and six cases of acute iritis.

In the ulcer cases, all of which had been treated previously a month medically, all reponded quickly after fever treatment but one. This one was a Wooren's ulcer, and there was no response after thirteen treatments.

In the iritis cases atropine had been used in all cases. Case 1 and 5 were of chronic recurring type. Time is required to direct final results. Patient 2 returned after two and half years with second type which promptly subsided after one fever treatment. Case 3 improved. 6 was striking. A severe iridocyclitis with secondary glaucoma, responded quickly and favorable to fever therapy. 
Bazin, 1862, reported the favorable influence of an acute infection of lycosis Fungoides. Wany others have noted dimilar influences since.

Motivated by the favorable influence of an acute infectious disease, Klauder (62) employed malaria treatment of a petient with hycosis fungoides and the kettering hypertherm in another. With both methods the eruption ceased. Itcing was slight. The patients resumed work and were in good general condition.

Corson treated a petient in the tumor stage with a cabinet in which the body temperature was raised by means of a spray of hot water. The patient was greatly improvea in four months.

The use of fever therapy in this aisease in only in the experimental stage. More cases will have to be studied efore the evidence will be worth while. 
CONCLUSION 
Although heat has been known as a therapeutic agent from the ancient times, the artificial production of it for therapeutic purooses has been in effect only since 1918 at which time malarial innculations were beginning to be used in production of fever in paretics. The production of $f \in v e r$ by various mechanical and electrical devices has been inaugerated within the last six years.

Since its inception artificial fever has been used to at ienpt to cure many diseases, in many cases with dubious results. Like all new discoveries in meaicine, artificial hyperpyrexia has made a wide field for the quack whose signs "Frienoly Fever" may be seen in neon lights in all large cities. Hotever, in certain diseases this new therapeutic agent has left no doubts as to its usefulness. These diseases are the various forms of syphilis, gonorrhe:, some forms of arthritis. A number of other diseases such as multiple sclerosis, asthma, some skin disease seem to be definitely helped by artificial fever, but more studies must be made before final conclusions may be arrived at.

The palm of distinction for special labor in this field must be accorded to nany, particularly the contribution of hitney and Kettering in relation to the perfection of hyperthermic agents of finest precision; a group of workers at the University of Rochester led by 
Conclusion

Carpenter, Warren and Boak; Columbia University with Bierman; the hayo Foundation with Desjardins, Hench abd slocumb and Sheard; and the inspirational labor of simpson and his group of morkers at the lliami valley hospital in Dayton.

Further simplification of methods is highly desiraole to lesen the disconfort, danger and expense of treatments. Regardiess of methods used, fever therapy will probably never be cheap. The physiological reactions induced thereby are so numerous and potent that during treatment patients must be constantly under observation and control of an attending nurse and physician. Fever therapy is not likely ever to be an office procedure.

A vast new field of therapy has been opened and definitely proven in a number of diseases. The field for future investigation is unlimited, aro it vill prove to be the treatment of choice in many conditions which today possess no adequate treatment. It can be preoicted with reasonable certainty that the pioneers in the field vill in the near future still more enrich our therapeutic resources. 
BIBLIUGRAPHY 


\section{Bibliography}

1. Annotations, The production of artificial pyrexia Lancet 226: 1348, June 23, 1934

2. Atsatt, R.F. and Patterson, L.E., Development of fever therapy in the Santa Barbara Hospital Arch. Phys. Therapy 16: 488-492, Aug. 1935

3. Atsatt, R.F. and Patterson, L.E., Fever therapy apparatus, Arch. Fhys. Therapy 17: 108-110, Feb. 1936

4. Balcar, T.O. and Sarsum, W.C. and Woodyatt, R.T., Fever and the water reserve of the body, Arch. Phys. Therapy 13: 389-399, July 1932

5. Baldwin, W.M. and Nelson, W.C., The histological effects produced in albino rats by high frequency currents, Proc soc Exper. Biol. and ised. $26: 588-590,1928$

6. Baldwin, W.M. and Dondale, burns in rats, Northwest Med. 32: 173-179,1933

7. Barbour, H.G., The heat regulating mechanism of the body, Physiol. Rev. 1: 295, April 21, 1921

8. Bazett, H.C., Alpers, B.J. and Erb, W.H., Hypothalamus and temperature control, Arch Neurol. and Psychiat. 30: 728-745, 1930

9. Bazett, H.C., Circulation in pyrexia, J. Lab. and Clin. Med. 18: 981-990, July 1933

10. Bazett, H.C., Temperature changes and their effect on circulation, Northwest ked. 32: 173-179,1933 
11. Berris, J.M., The treatment of arthritis by artificial fever, J. Aichigan W. Soc. 32: 355-358, June 1933

12. Bierman, T., Fever induced by short waves, Arch. Phys. Therapy 13: 389-391, July 1932

13. Bierman, W., Radiothermy, Arch. Phys. Therapy 13: 389-401, July 1932

14. Bierman, W., Radiothermy: Fever induced by short radio waves, Brit. J. Phys. Med. 7: 155-158, Dec. 1933

15. Bierman, W. and Fishberg, Ella, Some physiologic changes during hyperpyrexia, J.A.M.A. 103: 1354-1358, Nov. 3, 1934

16. Bischoff,F., Long, M. and Hill, Elsie, Studies in hyperthermia, J. Biol. Chem. 90: 321-329, Jan. 1931

17. Bischoff, Fritz, Maxwell, L.C., and Hill, Elsie, Studies in hyperthermia: 111 The phosphorous equilibrium, J. Biol. Chem. 90: 331-339, Jan. 1931

18. Bischoff, F., Ulmann, H.J., Hill, Elsie, Long, Louisa, Studies in hyperthermia induced by high frequency electric current, J. Biol. Chem. 85: 675-686, Feb. 1930

19. Bischoff, F., Long, Louise, and Hill, Elsie, Studies 


\section{Bibliography}

in hyperthermia: The acid base equilibrium,

J. Biol. Chem. 90: 321-329, Jan, 1931

20. Bishop, F.W., Horton, C.E. and Warren, S.L., A

Clinical study of artificial hyperthermia

induced by high frequency currents,

Am. J. H. Sc. 184: 515-533, 1932

21. Bishop, F.W., Lehman, R.N. and Warren, S.L., A comparison of three electrical methods of producing artificial hyperthermia, J.A.M.A. 104: 910915, March 16, 1935

22. Carpenter, C.M. and Boak, Ruth, Mucci, J.A. and

Warren, S.L., Studies on the physiologic effects of fever temperatures, J. Lab. and Clin. Med 18: 981-990, July 1933

23. Carpenter, C.M., Boak, Ruth, and Warren, S.L., The thermal death time of treponema pallidum in vitro, J. Exper. Med. 56: 741-750, Nov. 1932

24. Carpenter, C.M. and Page, A.B., The production of fever in man by short radio waves, science 71: $450-462,1930$

25. Carpenter, C.M. and Warren, S.L., Artificially induced fever in the treatment of disease, New York State J. Med. 32: 997-1001, sept. 1932 26. Christie, R. V. and Binger, Carl A., Experimental study of diathermy, J. Exper. Med. 46: 715-73, Nov. 1927 
27. Christie, R.V. and Loomis, A.L., The relation of high frequency to physiological effect of ultre high frequency currents, J. Exper. Hed. 49: 303-321, Feb. 1929

38. Cohen, P. and Warren, S.L., A study of the leucocytosis produced in man by artificial fever, J. Clin. Investigations 14: 423-433, July 1935

29. Council on Physical Therapy, Hyperpyrexia produced by physical agents, J.A.l.A.A. 103: 1308, Oct. 27, 1934

30. Council on Physical Therapy, The inductotherm J.A.M.A. 196: 1091, March 28, 1936

31. Desjardins, A.U., Fever therapy, Texas State J Med. 31: 194-200, July 1935

32. Desjardins, A.U., Stuhler, L.G. and Popp, W.C., Fever therapy of gonococci infection, J.A.M.A. 106: 690-699, Feb. 29, 1936

33. Draper, W.H., Hydrotherapy, External and internal, H. Rec., 43:481-485, 1893

34. Ecker, E.E. and O'Neal, N.W., Effects of hyperpyrexia induced by ultra high frequency currents on $B$. typhosus agglutinin and complement, Am. J. Pub. Health 22: 1050-1054, 0ct. 1932

35. Editorial, Electropyrexia

Arch. Phys. Therapy 26: 493-494, Aug. 1935 36. Epstein, S.H. and WcHugh, R.N., Therapeutic hyper- 


\section{Bibliography}

pyrexia induced by diathermy and electric blanket, Arch. Phys. Therapy 16: 32-35, Jan. 1935

37. Epstein, S.H., Hyperpyrexia at the Boston Psychopathic Hospital, New England J. Med. 212: 611613, April 4,1934

38. Epstein, N.N. and Cohen, M., The effect of hyperpyrexia produced by radiant heat in $\epsilon a r l y$ syphilis, J.A.H.A. 104: 883-889, March 16, 1935

39. Feinberg, S.M., Osborne, S.L, and Afremow, M.L., A new method of non-specific treatment of allergic disease, J. Allergy 2: 291, Feb 1931

40. Feinberg, S.M., Osborne, S.L. and Afremow, M.L., Fever by diathermy in the treatment of allergic disease, J. Allergy 2: 436-443, 1931

41. Feinberg, S.M., Osborne, S.L and Afremow, M.L., Sustained artificial fever in the treatment of intractable asthma, J.A.H.A. 99: 801-806, Sept. 3, 1932

42. Gale, C.K., A new air spaced cuff electrode, Arch. Phys. Therapy i7: 25-26, Jan. 1936

43 Gale, C.K., Penetrative and selective heat effects of short and ultrashort waves, Arch. Phys. Therapy 16: 271-277, May 1935 
44. Goldfeder, Anna, Radiothermy on oxygen content and capacity in human blood, Arch. Phys. Therapy 14: 339-340, June 1933

45. Hall, W.W. and Wakefield, I.G., A study of experimemtal heat stroke, J.A.M.A. 89: 177-182, 1927 46 Hartinan, E.W. and Major, R.C., Pathological changes from artificial fever, Am. J. Clin. Path. 5: 392-409, sept. 1935

47. Hench, P.S., Slocumb, C.H. and Popp, W.C., Fever therapy, J.A.M.A. 104: 1779-1790, May 18,1935

48. Hinsie, L.A. and Carpenter, C.M., Radiothermic treat ment of general paralysis, Psychiatric Quart 5: $215-224,1931$

49. Hopkins, Helen, Chemical changes in blood induced by hyperpyrexial baths, Arch. Neurol. and Psychiat. 31: 597-604, warch 1934

50. Hosmer, Helen, R., Heating effects in a high frequency static field, Science 68: 325-327, oct. 5, 1928

51. Hoverson, E.T., Horrow, G.W. and Hawthorne, R.O., Treatment of generaly paresis by typhoid vaccine and electric cabinet, Illino is K.J. 63: 252258, Harch 1933

52. Jacobsen, C. and Hesoi, K., Morphological changes in animal tissues due to heating by ultra high frequency oscillator, Arch. Path. 11: 744-759, 1931 
53. Jones, A.V., Experiences with hyperpyrexia by diathermy, Arch. Phys. Therapy 15: 155-163, March 1934

54. Jung, Ruth E. and Day, A.A., Effects of diathermy on concentration of complement and normal opsonins, Proc soc Exper Biol and yed. 28: 1080-1081, June 1931

55. Jung, Ruth I., Immunological studies in hyperpyrexia, Arch. Phys. Therapy 16: 387-404, July 1935 56. Kahler, H., Chalkley, H. and Vogelthin, C., Nature of effect of high frequency electric field upon Paramoecium, Pub. Health Rep. 44: 339, Feb. 15,1929

57. Karr, J.H. and Nasset, E.S., Physiologic effects of high frequency current, Am. J. Physiol. 107: 170-177, Jan. 1934

58. Keller, A.D. and Hare, H.K., Heat regulation in medullary and mid-brain preparations, Proc. Soc. Exper. Biol. and thed. 29: 1067-1069, 1931

59. Kendell, H.W., Webb, W.W. and Simpson, ..., Artificial fever therapy of gonorrheal arthritis, Am. J. Surg. 29: 428-435, sept. 1935

60. King, J.C. and Cocke, E. T., Therapeutic fever produced by diathermy, South. H. J. 23: 222228, Warch 1930 
Bibliography

61. Kissin, M. and Bierman, W., Influence of hyperpyrexia on velocity of blood flow, Proc soc. Ixper. Biol. and lied. 30: 527-530, Jan, 1933

62. Klauder, J., Fever therapy of Mycosis fungoicies, J.A.HA.A. 106: 201-205, Jan. 18,1936

63. Knudson, A., and Schaible, P.J., Physiologic and biochemical changes resulting from exposure to an ultra high frequency field, Arch. Path.11: 728-743, May, 1931

64. Kobak, D., Therapeutic heat, H. Rec. 250-254, Sept. 5, 1934

65. Kobak, D., Evaluation of hyperpyrexia Arch. Phys. Therapy 16: 481-488, Aug. 1935 66. Kohn, L.A. and Warren, S.I., Preliminary report on treatment of chronic and subacute infectious arthritis by artificial $f \in v \in r$, J. Clin. Investigation 12:871, sept. 1933

67. Kopp, I., Netabolic rates in therapeutic fever, Am. J. Wed. Sc. 190: 491-501, oct. 1935

68. Kundle, M.W., Hull, C.W. and Gentry, F.J., The effects of non-specific protein therapy on the blood and spinal fluid, J.A.H.A. 89: 13041308, oct. 15, 1927

69. Leopold,S.S. and Stewart, S.G., The effects of fever in bronchial asthma, J. Allergy 2: 425-435, sept. 1931 
70. Lewis, N.D.C., Fubbard, L.E. and Dyer, E.G.,

Malarial treatment of neurosyohilis, Am. J. Psychiat. 4: 175-221, oct. 1924

71. McQuarrie, Irvine and Stoesser, A.V., Influence of acute infection and of artificial fever on plasma lipoids, Proc Soc axper. Biol. and Vied. 29: 1281-1283, June 1933

73. Narkson, D.E. and osborne, S.L., The treatment of arthritis by sustained fever therapy, Illinois H.J. 60: 397-403, Nov. 1931

73. Larkson, D.E. and ocborne, S.L., Electropyrexia in treatment of chronic infectious arthritis, Illinois M.J. 64: 231-237. sept. 1933

74. Wehrtens, H.G. and Pouppirt, P.S., Hyperpyrexia produced by baths, Arch. Neurol. and Psychiat. 22: 700-708, oct, 1929

75. Menninger, W.C. and Fellows, R.w. Therapeutic fever produced by diathermy in generaly paralysis and tabes dorsalis, J.Kansas Soc. 32: 369-374, Nov. 1931

76. Merriman, J.R, and osborne, S.I., lethods of producing hyperpyrexia, IIIino is W.J. 64: 237240, Sept. 1933

77. Werriman, J.R., Holmquist, F.J., and osborne, S.L., A new method of producing heat in tissues. 
The inductotherm, Am. J. Led. Sc. 187: 677-683, way 1934

78. Willer, $H$. and Piness, G., Hyperthermia induced by high frequency current in treatment of intractable asthma, J. Allergy 2: 436-443, sept. 1931

79. Woen, J.K., hedes, G., Chalek, I., The relative effects of diathermy and infection on plasma proteins, J. Lab. and Clin. hed. 19: 571581, Warch 1934

80. Mortimer, B., Experimental hyperthermia induced by the high frequency current, Radiology 16: 705-719, May 1931

81. Mortimer, B. and Eeard, G., Tissue heating by short wave diathermy, J.A.M.A., 104: 510 Aug. 17, 1935

82. Mortimer, B. and Osborne, S.L., Tissue heating by short wave diathermy, J.A.iA.A. 104: 1413-1419, April 20, 1935

83. Nasset, E.S., Bishop, F.W. and Warren, S.L., Physiological effects of high frequency current Am. J. Physiol. 96: 439-448, Feb 1931

84. Neymann, C.H. and Osborne, S.L., Treatment of dementia paralytica, J.A.M.A. 96: 7-13, Jan. 3,1931 85. Neymamn, C.H., Feinberg, S.iA. and Markson, D.E., and osborne, S.L., Present status of electropyrexia Arch. Phys. Therapy 13: 749-768, Dec. 1932 
86. Neymann, C.H. and Osborne, S.L., The development of Hyperpyrexia, Arch Phys. Therapy 15: 149- 155, March 1934

87. Neymann, C.H. and Osborne, S.L., The physiology of electropyrexia, Am. J. Syph. and Neurol. 19: 28-35, Jan. 1934

88. Neymann, C.H. and Osborne, S.L., The treatment of some cases of multiple sclerosis by electropyrexia, J. Nerv. and Ment. Dis. 79: 423-433, April 1934

89. Nicholls, Edith E, Hannson, K.G. and Stainsby, W.J., Treatment of rheumatoid arthritis with hyperthermia. J. Bone \& Joint Surg. 16: 69-74, Jan. 1934

90. Osborne, S., Johnson, S.A. and Scupham, G., Effect of artificial fever on pulse changes of finger, Am. J. of Med. Sc. 190: 485-491, oct. 1935

91. Osler, William and WcCrae, Thomas, Principles and Practice of wedicine, ed 10, New York, Appleton \& Co., 378, 1925

92. Ott, I., The relation of the nervous system to the temperature of the body, J. Nerv. and Went. Dis. 11: $141-152,1884$

93. Perkins, C.T., Hyperthermia in dementia paralytica, New ngland J. Hed. 205: 374-380, Aug. 20, 1931 94. Perkins, C.T., Hyperthermia in dementia paralytica, Arch. Phys. Therapy 14: 461-468, Aug. 1933 
95. Phillips, K. and Shinkany, S., The value of hyperpyrexia in treatment of bronchial asthma, South. M.J. 28: 801-814, Sept. 1935

96. Popp, Walter. C., Pratical considerations of fever therapy, Proc Staff Meet., Mayo Clin. 10: 200-202, March 27, 1935

97. Reimann, H.H., Significance of fever and blood protein changes in regard to $d \in$ fense against infection, Ann Int. Hed. 6, 362-374, sept. 1932

98. Rosanoff, A.J., A simple thermotherapeutic technique, Am. J. Psychiat. 7: 489-492, Nov. 1927

99. Schamberg, J.G. and Rule, Anna M., Studies of the therapeutic effect of fever in experimental rabbit syphilis, Arch. Dermat, and Sybh. 14: 243-245, sept. 1926

100. Schamberg, J.G. and Butterworth, H., Diathermy in the treatment of generaly paralys is and in Wasserman-fast syphilis, Am. J. Syph 16: 619533,1932

101. Schamberg, J. and Tseng, H., Experimerta of therapeutic value of hot baths, Am. J. Syph. and Neuro1. 11: 337-397, July 1927

102. Shroeder, K., The sulfosin treatment of generaly paralysis, Lancet 2: 1081-1084, Nov 23, 1929 103. Schmidt, W.H., Artificial fever therapy Arch. Phys. Therapy 14: 281-285, Hay 1933 
104. Simpson, W.M., Influence if radiotherm pyretotherapy on chloride metabolism, J.A.M.A. 100: 6768, Jan 7, 1933

105. Simpson, T.M. Kislig, F.K. and Sirrler, E.C., Ultra- high frequency pyretotherapy in neurosyphilis, Ann. Int. Med. 7: 64-75, July 1933 106. Simpson, H.M., Artificial fever therapy, Proc. Staff Mett., Hayo Clin. 9: 567-571, sept. 19, 1934

107. Simpson, w. W., Artificial fever therapy of syphilis J.A.A.A. 105: 2132-2140, Dec 28, 1935

108. Solomon, H.C., Berk, A., Theiler, H. and Clay, C.L., The use of sodoku in thetreatment of general paralysis Arch. Int. Wed: 38: 391-404, sept 18,1926 109. Stuhler, L.G., Fever therapy of gonococcal infection, Proc. Staff. Meet., Wayo Clin. 10: 207-208, liarch 27,1935

110. Tenney, C.F., Artificial fever produced by the short wave radio and its therapeutic application, Ann. Int. Hed. 6: 457-468, oct. 1932

111. Turre11, i.J., Short wave therapy

Arch. Phys. Therapy 26: 724-732, Dec. 1935

112. Urechia, C., Pyogenic principles in human urine ab J.A.M.A. 105: 1561, Nov. 9, 1935

113. Warren, S.L. and Wilson, K.M., The treatment of 
gonococcal infections by attificial hyperthermia, Am. J. Obst. and Gynec. 24: 59z598 , oct 1932

114. Weiss, B.P., Further observation in the treatment of mutliple sclerosis by hyperpyrexia, H. Rec. 142: 489-493

115. Welch, William $\mathrm{H}$, on general pathology of fever M. News 52: 393-493, Dec. 4, 1935

116. Whitney, E.L., Fever therapy in treatment of corneal ulcer, J.A.W.A. 104: 1794-1799, Aug. 1935

117. Wiggers, C.J. and orias, 0., Circulatory changes during radiotherny, Am. J Physiol. 100: 614628, Warch 1932

118. Nilgus, S.L. and Lurie, L. Fever treatment in paresis, Arch. Neurol. and Psychiat. 26: 662-664, Sept. 1931

119. Wilgus, S.D. and Lurie, L., The fever treatment of paresis by means of diathermy current and electric blanket, Illinois $4 . J .60: 341-344$, oct. 191 